The University of Maine

DigitalCommons@UMaine

Marine Sciences Faculty Scholarship

School of Marine Sciences

$11-1-2019$

\title{
Algorithm to derive inherent optical properties from remote sensing reflectance in turbid and eutrophic lakes
}

\author{
Kun Xue \\ Nanjing Institute of Geography and Limnology Chinese Academy of Sciences \\ Emmanuel Boss \\ University of Maine, emmanuel.boss@maine.edu \\ Ronghua Ma \\ Nanjing Institute of Geography and Limnology Chinese Academy of Sciences \\ Ming Shen \\ Nanjing Institute of Geography and Limnology Chinese Academy of Sciences
}

Follow this and additional works at: https://digitalcommons.library.umaine.edu/sms_facpub

Part of the Oceanography and Atmospheric Sciences and Meteorology Commons

\section{Repository Citation}

Xue, Kun; Boss, Emmanuel; Ma, Ronghua; and Shen, Ming, "Algorithm to derive inherent optical properties from remote sensing reflectance in turbid and eutrophic lakes" (2019). Marine Sciences Faculty Scholarship. 166.

https://digitalcommons.library.umaine.edu/sms_facpub/166

This Article is brought to you for free and open access by DigitalCommons@UMaine. It has been accepted for inclusion in Marine Sciences Faculty Scholarship by an authorized administrator of DigitalCommons@UMaine. For more information, please contact um.library.technical.services@maine.edu. 


\title{
applied optics
}

\section{Algorithm to derive inherent optical properties from remote sensing reflectance in turbid and eutrophic lakes}

\author{
Kun Xue, ${ }^{1}$ Emmanuel Boss, ${ }^{2}$ (1) Ronghua Ma, ${ }^{1, *}$ and Ming Shen ${ }^{1,3}$ \\ ${ }^{1}$ Key Laboratory of Watershed Geographic Sciences, Nanjing Institute of Geography and Limnology, Chinese Academy of Sciences, 73 East \\ Beijing Road, Nanjing 210008, China \\ ${ }^{2}$ School of Marine Sciences, University of Maine, Orono, Maine 04469, USA \\ ${ }^{3}$ University of Chinese Academy of Sciences, Beijing 100049, China \\ *Corresponding author: rhma@niglas.ac.cn
}

Received 15 August 2019; revised 23 September 2019; accepted 23 September 2019; posted 23 September 2019 (Doc. ID 375485); published 31 October 2019

\begin{abstract}
Inherent optical properties play an important role in understanding the biogeochemical processes of lakes by providing proxies for a variety of biogeochemical quantities, including phytoplankton pigments. However, to date, it has been difficult to accurately derive the absorption coefficient of phytoplankton $\left[a_{p}(\lambda)\right]$ in turbid and eutrophic waters from remote sensing. A large dataset of remote sensing of reflectance $\left[R_{r s}(\lambda)\right]$ and absorption coefficients was measured for samples collected from lakes in the middle and lower reaches of the Yangtze River and Huai River basin (MLYHR), China. In the process of scattering correction of spectrophotometric measurements, the particulate absorption coefficients $\left[a_{p}(\lambda)\right]$ were first assumed to have no absorption in the near-infrared (NIR) wavelength. This assumption was corrected by estimating the particulate absorption coefficients at $750 \mathrm{~nm}$ $\left[a_{p}(750)\right]$ from the concentrations of chlorophyll-a (Chla) and suspended particulate matter, which was added to the $a_{p}(\lambda)$ as a baseline. The resulting mean spectral mass-specific absorption coefficient of the nonalgal particles (NAPs) was consistent with previous work. A novel iterative IOP inversion model was then designed to retrieve the total nonwater absorption coefficients $\left[a_{n w}(\lambda)\right]$ and backscattering coefficients of particulates $\left[b_{b p}(\lambda)\right], a_{p}(\lambda)$, and $a_{d g}(\lambda)$ [absorption coefficients of NAP and colored dissolved organic matter (CDOM)] from $R_{r s}(\lambda)$ in turbid inland lakes. The proposed algorithm performed better than previously published models in deriving $a_{n w}(\lambda)$ and $b_{b p}(\lambda)$ in this region. The proposed algorithm performed well in estimating the $a_{p b}(\lambda)$ for wavelengths $>500 \mathrm{~nm}$ for the calibration dataset $[\mathrm{N}=285$, unbiased absolute percentage difference (UAPD) $=55.22 \%$, root mean square error $\left.(\mathrm{RMSE})=0.44 \mathrm{~m}^{-1}\right]$ and for the validation dataset $\left(\mathrm{N}=57, \mathrm{UAPD}=56.17 \%, \mathrm{RMSE}=0.71 \mathrm{~m}^{-1}\right)$. This algorithm was then applied to Sentinel-3A Ocean and Land Color Instrument (OLCI) satellite data, and was validated with field data. This study provides an example of how to use local data to devise an algorithm to obtain IOPs, and in particular, $a_{p h}(\lambda)$, using satellite $R_{r s}(\lambda)$ data in turbid inland waters. () 2019 Optical Society of America
\end{abstract}

\section{INTRODUCTION}

Inherent optical properties (IOPs), including the absorption $[a(\lambda)]$ and backscattering $\left[b_{b}(\lambda)\right]$ coefficients of water constituents [e.g., water, nonalgal particles (NAP), phytoplankton, and colored dissolved organic matter (CDOM)], are the key determinants of ocean color remote sensing and the underwater light field. The spectral absorption coefficients of water constituents include absorption of water itself $\left[a_{w}(\lambda)\right]$, phytoplankton $\left[a_{p h}(\lambda)\right], \operatorname{NAP}\left[a_{d}(\lambda)\right]$, and $\operatorname{CDOM}\left[a_{g}(\lambda)\right] . a_{p h}(\lambda)$ is mainly used to infer pigment concentrations [1-3], primary production $[4,5]$, phytoplankton carbon [6,7], and phytoplankton community composition [8-11]. Deriving the $a_{p h}(\lambda)$ rather than chlorophyll-a concentrations (Chla) from remote sensing reflectance $\left[R_{r s}(\lambda)\right]$ was recommended for different regions and seasons of highly turbid inland waters [12-14]. In addition, the $a_{p h}(\lambda)$ is desirable to better understand the biogeochemical processes of waters at regional scales [5], especially in turbid productive waters $[15,16]$.

Many IOP inversion algorithms, including semianalytical inversion algorithms (SAAs) [17-19] and empirical approaches $[20,21]$, have been developed to estimate the absorption and backscattering coefficients of water constituents in oceanic, coastal, and inland waters. Among these algorithms, two solution schemes are used: (1) a simultaneous solution of IOPs of 
the water components and (2) a two-part solution in which the backscattering coefficients of particulate $\left[b_{b p}(\lambda)\right]$ and $a(\lambda)$ are first determined, and then $a(\lambda)$ is decomposed into its components [22]. These approaches usually require assumptions about spectral shapes, e.g., exponential functions for $a_{d}(\lambda)$ and $a_{g}(\lambda)$, and spectral parameterization of $a_{p h}(\lambda)$ [23,24]. Most of these algorithms have been found to be effective in oceanic waters optically dominated by phytoplankton; however, they often fail in optically complex inland waters with high CDOM and NAP contents [22]. In inland waters, NAP and CDOM often have high magnitude and large variability, and do not covary with phytoplankton. Published studies for other inland and coastal waters (e.g., the Boreal lakes of southern Finland [25], the coastal areas of the Baltic sea [26], Lake Erie [27]), and the NOMAD dataset (NASA bio-Optical Marine Algorithm Dataset) [28] had lower total absorption coefficients compared to the case we study here, and were dominated by $a_{p h}(443)$ and $a_{g}(443)$, or were codominated by $a_{p h}-a_{g}$ at $443 \mathrm{~nm}$, with a contribution by $a_{d}(443)$ lower than $40 \%$ [29].

Previous studies have found that both the magnitude and proportion of the absorption coefficient of water constituents determine the applicability of an IOP inversion algorithm for specific conditions [30]. Several IOP inversion algorithms suitable for inland waters have been developed based on the bio-optical properties of the specific study region to derive $a(\lambda)$ (e.g., [31,32]) and the absorption coefficients of water constituents [e.g., 7,16,33]. Among these algorithms, quasi-analytical algorithms (QAAs) [18] and QAA-based algorithms [14,16,34] have advantages in their ease in changing the parameterizations of the empirical steps of the algorithms. At present, the modified QAA algorithms can be applied to $R_{r s}(\lambda)$ data from multispectral sensors, such as Medium Resolution Imaging Spectrometer (MERIS) and Ocean and Land Color Instrument (OLCI) to retrieve the $a_{p h}(\lambda)$ in optically complex waters by changing the reference wavelengths to the red and infrared (IR) wavelengths (e.g., 665, 709, or $750 \mathrm{~nm}$ ) [15,29,35]. A combination of the near-IR (NIR)-based and QAA-based algorithm was built to estimate IOP products for both the open ocean and turbid coastal/inland waters [36]; whereas, the NIR-based model did not perform well in in situ hyperspectral $R_{r s}(\lambda)$ due to its large noise in the wavelengths $>800 \mathrm{~nm}$. Overall, estimating the spectra of $a_{p h}(\lambda)$ in waters where phytoplankton are not optically dominant is still a challenge due mainly to the dominance of NAP and CDOM [16].

The middle and lower reaches of the Yangtze and Huai River (MLYHR) in China contain approximately 760 lakes $\left(\sim 15,102 \mathrm{~km}^{2}\right)$, with areas ranging from $\sim 0.1 \mathrm{~km}^{2}$ to $\sim 3960 \mathrm{~km}^{2}$ [37]. Characterized by the ternary absorption budget at $443 \mathrm{~nm}$, the lakes in the MLYHR basin were found to be mostly dominated by $a_{d}(443)$ or to be codominated by $a_{d}(443)$ and $a_{p h}(443) \quad[29,38]$. An IOP inversion algorithm (denoted as QAA750) that is suitable for optically complex lakes in the lower reaches of the Yangtze River, China, was developed by shifting the reference wavelength to $750 \mathrm{~nm}$ [29]. The $a_{p h}(675)$ was derived from the inverted $a(\lambda)$ at 665 and $674 \mathrm{~nm}$, where the contributions of NAP and CDOM were low. However, this algorithm failed to derive reasonable $a_{p h}(\lambda)$ spectra, as the acceptable uncertainties in the derived $a_{d}(\lambda)$ values introduced large errors into the $a_{p h}(\lambda)$, which has lower magnitude. In addition, the field data we used [29] were measured using the quantitative filter technique (QFT) in transmittance mode (T-mode), which has uncertainties from the unknown level of absorption in the NIR due to the unknown scattering offset [39]. Therefore, the null assumption at $750 \mathrm{~nm}$ previously applied for our measurements likely introduces errors in waters with high NAP absorption in the NIR range [40].

In this paper, building upon QAA750 [29], a novel inversion algorithm is developed to estimate IOPs using $R_{r s}(\lambda)$ from field-measured data and Sentinel-3A/OLCI images of lakes in the MLYHR basin. The aims of this study are to (1) estimate the particulate absorption coefficient at $750 \mathrm{~nm}\left[a_{p}(750)\right]$ to correct the $a_{p}(\lambda)$ measured using the T-mode, (2) develop an IOP inversion algorithm that is applicable to optically complex lakes based on the field hyperspectral $R_{r s}(\lambda)$ data and is validated with measured IOP data, and (3) apply the proposed algorithm to Sentinel-3A/OLCI $R_{r s}(\lambda)$ data. This study provides an improved inversion algorithm to monitor the IOPs in turbid and eutrophic lakes.

\section{STUDY REGION AND DATASETS}

\section{A. Study Region}

The MLYHR basin encompasses the five largest freshwater lakes in China, including Lake Poyang, Lake Dongting, Lake Taihu, Lake Hongze, and Lake Chaohu (Fig. 1). Most of the lakes are turbid with low Secchi disk depths; for example, the mean Secchi disk depths for the five largest freshwater lakes range from 17.1 to $53.7 \mathrm{~cm}$. Frequent algal blooms, resuspended sediments, dredging activities, and river inflows are the main causes for IOP variations in these lakes [41-44].

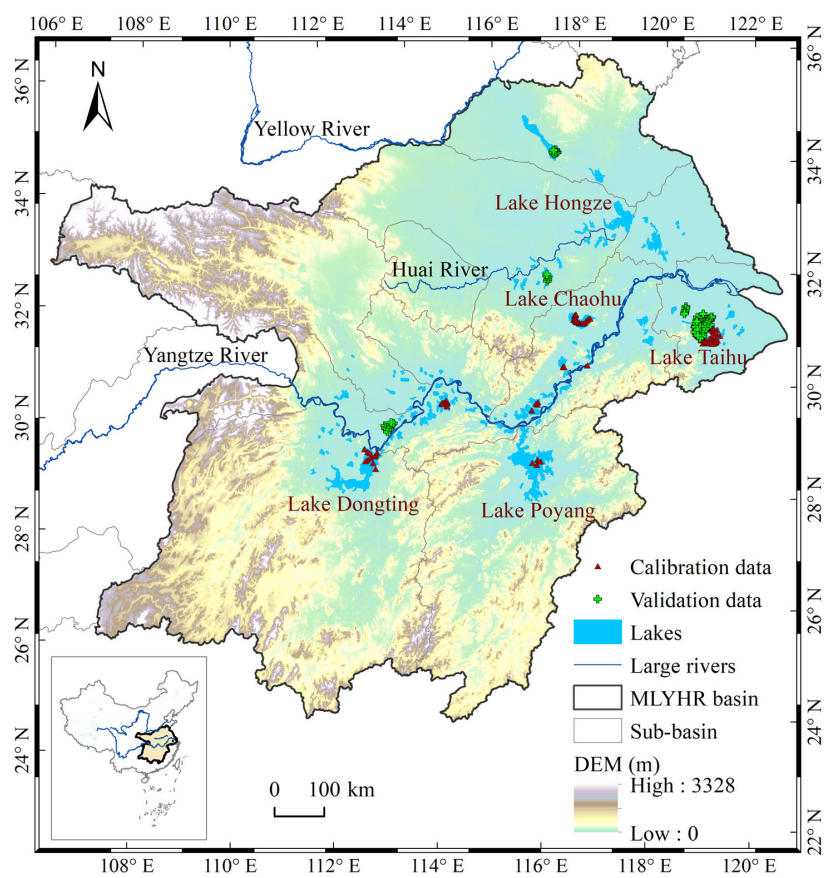

Fig. 1. Sampling stations and locations of lakes in the middle and lower reaches of the Yangtze and Huai River (MLYHR) basin in China. 


\section{B. Field Data}

Field data were collected during 16 survey cruises (342 distinct stations) from October 2008 to July 2018 in the lakes located in the MLYHR basin (Fig. 1). Remote sensing reflectance, $R_{r s}(\lambda)$, spanning from 350 to $1050 \mathrm{~nm}$ with an interval of $1 \mathrm{~nm}$, was estimated from measurements with an ASD field spectrometer (FieldSpec Pro Dual VNIR, Analytical Spectra Devices, Inc.) using the method of [45]; the water-leaving radiance $\left[L_{w}(\lambda)\right]$ was derived from the above-water upwelling radiance $\left[L_{u}(\lambda)\right]$ by removing the influence of the sky radiance $\left[L_{s k y}(\lambda)\right]$ using a reflectance ratio $(\rho)$ and measuring at a viewing direction of $40 \mathrm{deg}$ from the nadir and $135 \mathrm{deg}$ from the sun. The downwelling plane irradiance $\left[E_{d}(\lambda)\right]$ was derived from the measured radiance of a gray Lambertian panel $\left[L_{p}(\lambda)\right]$,

$$
R_{r s}(\lambda)=\frac{L_{w}(\lambda)}{E_{d}(\lambda)}=\frac{L_{u}(\lambda)-\rho \times L_{\text {sky }}(\lambda)}{L_{p}(\lambda) \times \pi / \rho_{p}},
$$

where $\rho_{p}$ is the reflectance of the reference board. Considering the average wind speed $(<5 \mathrm{~m} / \mathrm{s}$ ) and sky conditions (under clear sky or low cloud), $\rho$ was assumed to be 0.028 , based on the lookup table for $\rho$ in [45].

The absorption of total particulate matter, $a_{p}(\lambda)$, was determined using the QFT in the T-mode with a Shimadzu UV2600 spectrophotometer [46,47]. $a_{d}(\lambda)$ was measured after the pigments were bleached with sodium hypochlorite [48], and the $a_{p h}(\lambda)$ was the difference between $a_{p}(\lambda)$ and $a_{d}(\lambda)$. The absorbance spectra of particulates were corrected using the null NIR assumption by subtracting the absorbance at $750 \mathrm{~nm}$ from the entire spectra. Path length amplification was corrected using the method in Refs. [25,49,50]. Note that the null NIR assumption leads to underestimation of $a_{d}(\lambda)$ and $a_{p}(\lambda)$ in waters with high NAP [39]. Here, we correct this assumption by adding back an estimation of $a_{p}$ (750) (Appendix A).

The water samples were filtered using $0.22 \mu \mathrm{m}$ pore size filters, and the $a_{g}(\lambda)$ values of the water samples $(280$ to $700 \mathrm{~nm}$ with $1 \mathrm{~nm}$ interval) were measured using a Shimadzu UV2600 spectrophotometer with a $1 \mathrm{~cm}$ cuvette. The total absorption coefficient spectrum $[a(\lambda)]$ is the sum of $a_{p h}(\lambda), a_{d}(\lambda), a_{g}(\lambda)$ and the absorption coefficients of pure water $\left[a_{w}(\lambda)\right][51]$,

$$
a(\lambda)=a_{p h}(\lambda)+a_{d}(\lambda)+a_{g}(\lambda)+a_{w}(\lambda) .
$$

The total nonwater absorption coefficient $\left[a_{n w}(\lambda)\right]$ is the sum of $a_{p h}(\lambda)$ and $a_{d g}(\lambda)$, which is the sum of $a_{d}(\lambda)$ and $a_{g}(\lambda)$,

$$
\begin{gathered}
a_{n w}(\lambda)=a_{p h}(\lambda)+a_{d g}(\lambda), \\
a_{d g}(\lambda)=a_{d}(\lambda)+a_{g}(\lambda) .
\end{gathered}
$$

Chla was obtained by measuring pigments extracted with $90 \%$ acetone using a Shimadzu UV2600 spectrophotometer [52,53]. Suspended particulate matter (SPM) was determined gravimetrically from samples collected on precombusted and preweighed GF/F filters in the laboratory [54]. Suspended particulate inorganic matter (SPIM) was derived gravimetrically by burning organic matter from the filters after drying at $105^{\circ} \mathrm{C}$ for $4-6 \mathrm{~h}$. The total backscattering coefficients $\left[b_{b}(\lambda)\right]$ were measured with a HydroScat-6 Spectral Backscattering Sensor (HS6) at six wavelengths, centered at 420, 442, 470, 510, 590, and $700 \mathrm{~nm}$.
Additional details regarding the measurements and processing methods for deriving the $R_{r s}(\lambda)$, absorption coefficients, and backscattering coefficients can be found in Refs. [29,55,56].

\section{Sentinel 3A/OLCI Data}

The OLCI on Sentinel-3A has 21 spectral bands (400$1020 \mathrm{~nm}$ ) with high signal-to-noise ratios and $300 \mathrm{~m} \times 300 \mathrm{~m}$ pixel sizes. The OLCI Level-1B full-resolution data (OL_1_EFR, $300 \mathrm{~m}$ ) over the studied lakes were downloaded from the European Space Agency (ESA) Copernicus Open Access Hub (https://scihub.copernicus.eu/dhus/\#/home). The vector version of the $6 \mathrm{SV}$ model (the second simulation of the satellite signal in the solar spectrum correction scheme) [57] was used to derive the $R_{r s}(\lambda)$ from cloud-free Level-1B OLCI images. The continental aerosol type and middle latitude atmospheric profiles of the 6SV model were used, and the aerosol optical thickness retrieved by the Aqua/Terra Moderate Resolution Imaging Spectroradiometer (MODIS) over the lakes on the same day were set as input parameters to the 6SV model. $R_{r s}(\lambda)$ derived using $6 \mathrm{SV}$ was compared with $R_{r s}(\lambda)$ derived from Case 2 Regional Coast Color processor (C2RCC) [58] and polynomial-based algorithm applied to MERIS (POLYMER) [59]. It indicated that 6SV performed better than C2RCC and POLYMER in this region [29,60]. Algal blooms (coverage area $>=10 \%$ ) were masked using the floating algae index (FAI) [61] and the algae pixel-growing algorithm (APA) [62] due to the large errors associated with the atmospheric correction for these waters [63]. For comparison with in situ data and algorithm development, $R_{r s-O L C I}$ was derived from fieldmeasured $R_{r s}(\lambda)$ values using the spectral response function (SRF) of OLCI (https://earth.esa.int/web/sentinel/userguides/sentinel-3-olci),

$$
R_{r s-\mathrm{OLCI}}(i)=\frac{\int_{\lambda_{1}}^{\lambda_{2}} R_{r s}(\lambda) \times \operatorname{SRF}(\lambda, i) \mathrm{d} \lambda}{\int_{\lambda_{1}}^{\lambda_{2}} \operatorname{SRF}(\lambda, i) \mathrm{d} \lambda},
$$

where $i$ represents the $i$ th band of OLCI, from 1 to 21 . The measured absorption coefficients were processed similarly for comparison with those derived from the OLCI data.

\section{METHODS}

In this study, the in situ particulate absorption data are first corrected by estimating $a_{p}(750)$ (Appendix A). An iterative IOP inversion model (Section 3.A) is then designed to derive $a_{n w}(\lambda)$, $b_{b p}(\lambda), a_{p h}(\lambda)$, and $a_{d g}(\lambda)$ using the field $R_{r s}(\lambda)$ as input, and is validated using the corrected in situ absorption coefficients. This model is applied to the OLCI data (Section 3.B) and compared to two other IOP inversion models (Section 3.C) that are also optimized using the in situ data.

\section{A. Novel Iterative IOP Inversion Algorithm - Development with In Situ Data}

A novel iterative IOP inversion model for turbid and eutrophic waters is developed using field-measured data (Fig. 2) and is described as follows. 


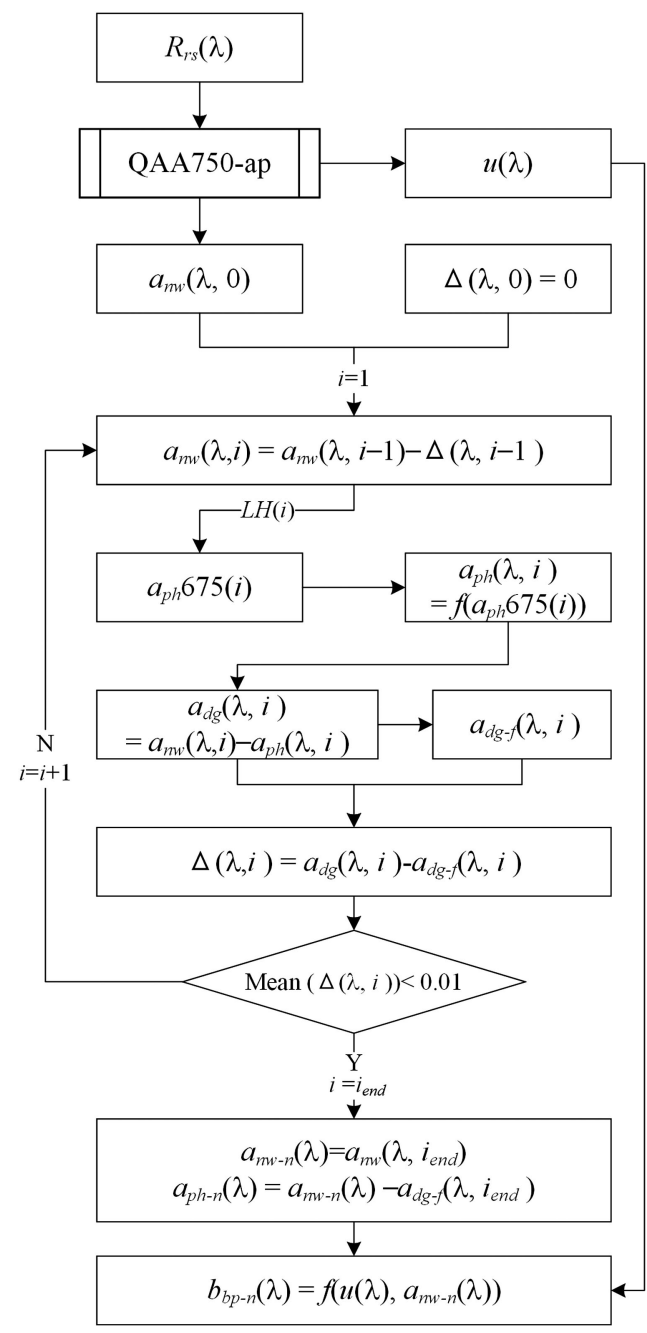

Fig. 2. Flow chart of the proposed IOP algorithm for fieldmeasured data. Remote sensing reflectance $\left[R_{r s}(\lambda)\right]$ is the input parameter obtained from field measurements. $u(\lambda)=b_{b}(\lambda) /$ $\left(a(\lambda)+b_{b}(\lambda)\right)$. Details of QAA750-ap are described in Table 1.

\section{Update of Part I of QAA750 (QAA750-ap)}

Part I of QAA750 (Table 3 in Ref. [29]) was built to derive $a_{n w}(\lambda)$ and $b_{b p}(\lambda)$ based on the zero absorption assumption for $a_{p}$ (750); in this study, $a_{p}$ (750) computed using the method in Appendix A was added to Part I of the QAA750 algorithm to improve the estimation of $a_{n w}(\lambda)$ and $b_{b p}(\lambda)$ (Table 1$)$.

For the inversion model from remote sensing, we use two new bio-optical relationships derived from our in situ data to estimate Chla [root mean square error $(\mathrm{RMSE})=50.41 \mathrm{mg} / \mathrm{m}^{3}$, unbiased absolute percentage difference $(\mathrm{UAPD})=44.38 \%$, $\left.R^{2}=0.58\right]$ and SPM (RMSE $=43.54 \mathrm{~g} / \mathrm{m}^{3}, \quad \mathrm{UAPD}=$ $35.63 \%, R^{2}=0.51$ ) from $R_{r s}$ (Fig. 3 ),

$$
\begin{aligned}
\text { Chla } & =22.68\left[\frac{R_{r s}(709)}{R_{r s}(675)}\right]^{3.32}, \\
\mathrm{SPM} & =1417.60 \times R_{r s}(709)^{0.95} .
\end{aligned}
$$

In QAA750-ap, the relationship between $R_{r s}$ and $b_{b} /\left(a+b_{b}\right)$ is modeled by defining

$$
\begin{gathered}
u(\lambda)=\frac{b_{b}(\lambda)}{a(\lambda)+b_{b}(\lambda)}, \\
r_{r s}(\lambda)=g_{0} u(\lambda)+g_{1} u(\lambda)^{2},
\end{gathered}
$$

where, $g_{0}=0.084$ and $g_{1}=0.17$ [64]. $r_{r s}(\lambda)$ is the subsurface remote sensing reflectance and is derived from $R_{r s}(\lambda)$, according to Lee et al. [18],

$$
r_{r s}(\lambda)=\frac{R_{r s}(\lambda)}{0.52+1.7 R_{r s}(\lambda)} .
$$

$b_{b}(\lambda)$ is the sum of backscattering coefficient of pure water $\left[b_{b w}(\lambda)\right][65]$ and $b_{b p}(\lambda)$, which is expressed as a power-law function,

$$
b_{b p}(\lambda)=b_{b p}(750)\left(\frac{750}{\lambda}\right)^{\mathrm{Y}}
$$

However, with our field dataset, $b_{b p}(\lambda)$ derived from the measured $a_{n w}(\lambda)$ and $u(\lambda)$ does not follow a power-law function well [Fig. 4(a)]. Hence, if the QAA750-ap-derived $b_{b p}(\lambda)$ was used in estimating $a_{n w}(\lambda)$ (step 8 of Table 1), there would be a difference between the model-derived and measured $a_{n w}(\lambda)$, especially for wavelengths $>550 \mathrm{~nm}$ [Fig. 4(b)]. The differences between the field $a_{n w}(\lambda)$ and model-derived $a_{n w}(\lambda)$ in Fig. 4(b) may come from the assumptions of the QAA750-ap model and/or the power function of $b_{b p}(\lambda)$. When decomposing $a_{n w}(\lambda)$ into $a_{d g}(\lambda)$ and $a_{p h}(\lambda)$, if we subtract an analytical model of $a_{d g}(\lambda)$ from $a_{n w}(\lambda)$ directly, the uncertainties associated with $a_{n w}(\lambda)$ would lead to an overestimation of $a_{p h}(\lambda)$ in the wavelengths from 550 to $750 \mathrm{~nm}$ (we find these values to be up to twice too large).

\section{Iterative Approach to Derive IOPs}

To remove the residuals from the first guess of model-derived $a_{n w}(\lambda)$, an iterative approach was developed to estimate the $a_{p h}(\lambda)$ and $a_{d g}(\lambda)$, and then to derive new $a_{n w}(\lambda)$ and $b_{b p}(\lambda)$. When $i=1, a_{n w}(\lambda, i-1)$ is the QAA750-apderived $a_{n w}(\lambda, I=0) . a_{p h}(\lambda)$ at $675 \mathrm{~nm}$ of the $i$ th iteration $\left[a_{p h} 675(i)\right]$ is derived from the absorption line height around $675 \mathrm{~nm}[\mathrm{LH}(i)]$, calculated from $a_{n w}(\lambda)$ values at 650,675 , and $715 \mathrm{~nm}[67]$,

$$
\begin{aligned}
\operatorname{LH}(i) & =a_{n w}(675, i)-\frac{715-675}{715-650} a_{n w}(650, i) \\
& -\frac{675-650}{715-650} a_{n w}(715, i) .
\end{aligned}
$$

The relationship between $a_{p h} 675(i)$ and $\mathrm{LH}(i)$ is fitted using a power-law function $\left(\mathrm{RMSE}=0.33 \mathrm{~m}^{-1}, \mathrm{UAPD}=17.85 \%\right.$, $\left.\mathrm{R}^{2}=0.94\right)$ as follows:

$$
a_{p h} 675(i)=A_{0} \times \mathrm{LH}(i)^{A_{1}} .
$$

The parameters $\left[A_{0}=1.53( \pm 0.02), A_{1}=0.97( \pm 0.01)\right]$ are determined using $\mathrm{LH}$ derived from measured $a_{n w}(\lambda)$ and measured $a_{p h} 675$ [Fig. 5(a)]. The relationship between the field $a_{p h} 675$ and LH derived from QAA750-ap-derived $a_{n w}(\lambda, i=0)$ is compared to that of LH derived from field $a_{n w}(\lambda)$ [Fig. 5(a)]. 
Table 1. Steps of the QAA750-ap Algorithm ${ }^{a}$

\begin{tabular}{|c|c|c|c|}
\hline Step & Property & Expression & Source \\
\hline 1 & $r_{r s}(\lambda)$ & $r_{r s}(\lambda)=R_{r s}(\lambda) /\left(0.52+1.7 R_{r s}(\lambda)\right)$ & literature-based [18] \\
\hline \multirow[t]{2}{*}{2} & $u(\lambda)$ & $u(\lambda)=\frac{b_{b}(\lambda)}{a(\lambda)+b_{b}(\lambda)}$ & \\
\hline & & $u(\lambda)=\frac{-g_{0}+\left[\left(g_{0}\right)^{2}+4 g_{1} r_{r s}(\lambda)\right]^{1 / 2}}{2 g_{1}} g_{0}=0.084$ & literature-based [64] \\
\hline 3 & $a(750)$ & $a(750)=a_{w}(750)+a_{p}(750)$ & - \\
\hline 4 & $a_{p}(750)$ & $\begin{array}{c}a_{p}(750)=(1-f r) \times a_{d}{ }^{*}(750) \times \mathrm{SPM} \\
=(\mathrm{SPM}-0.37 \mathrm{Chla}) \times a_{d}{ }^{*}(750) \\
a_{p}^{*}(750)=0.014 \\
\text { Chla }=22.68\left[\frac{R_{r s}(709)}{R_{r s}(675)}\right]^{3.32} \\
\mathrm{SPM}=1417.6 \times R_{r s}(709)^{0.95}\end{array}$ & using local data and $a_{d}^{*}(750)$ from $[40]$ \\
\hline 5 & $b_{b p}(750)$ & $b_{b p}(750)=\frac{u(750) \times a(750)}{1-u(750)}-b_{b \mathrm{w}}(750)$ & definition of $u(\lambda)$ \\
\hline 6 & $\mathrm{Y}$ & $\mathrm{Y}=3.99-3.59 \exp \left[-0.9 \frac{r_{r s}(443)}{r_{r}(560)}\right]$ & optimized using Ecolight simulation data \\
\hline 7 & $b_{b}(\lambda)$ & $b_{b}(\lambda)=b_{b p}(750)\left(\frac{750}{\lambda}\right)^{\mathrm{Y}}+b_{b w}(\lambda)$ & assumption regarding shape of $b_{b p}(\lambda)$ \\
\hline 8 & $a_{n w}(\lambda)$ & $a_{n w}(\lambda)=\frac{(1-u(\lambda)) b_{b}(\lambda)}{u(\lambda)}-a_{w}(\lambda)$ & definition of $u(\lambda)$ \\
\hline
\end{tabular}

"Steps with gray backgrounds were improved based on Part I of QAA750 (Table 3 in Ref. [29]).
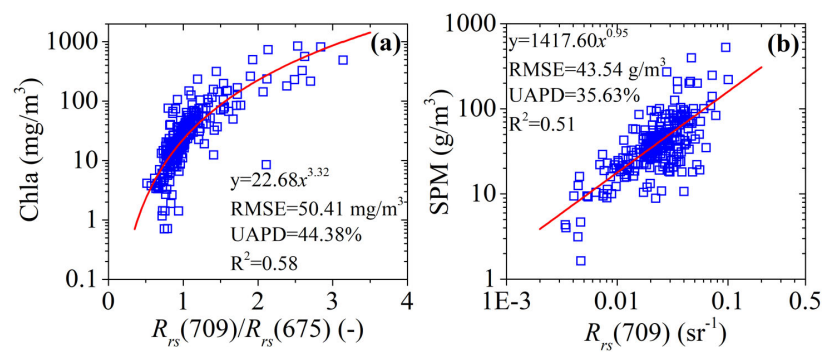

Fig. 3. (a) Relationship between Chla and $R_{r s}(709) / R_{r s}(675)$. (b) Relationship between SPM and $R_{r s}$ (709).
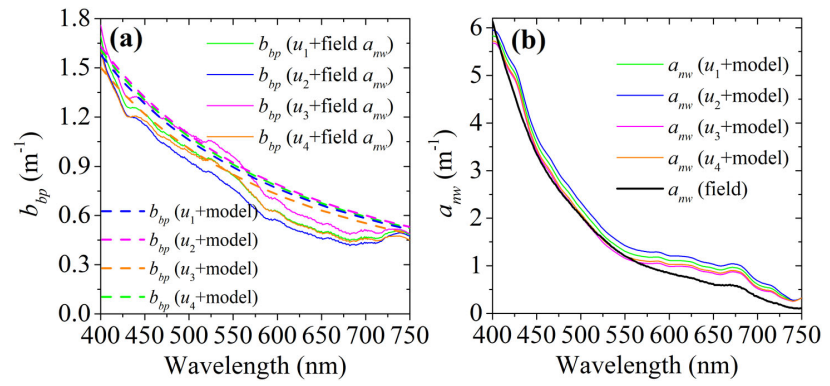

Fig. 4. (a) Example of $b_{b p}(\lambda)$ derived from measured $a_{n w}(\lambda)$ and $u(\lambda)$ (solid lines), and QAA750-ap derived $b_{b p}(\lambda)$ (dashed lines) with different $g_{0}$ and $g_{1}$ values: $u_{1}\left(g_{0}=0.084, g_{1}=0.17\right.$, [64]); $u_{2}$ $\left(g_{0}=0.089, g_{1}=0.125,[18]\right) ; u_{3}\left(g_{0}=0.0949, g_{1}=0.0794,[66]\right)$; $u_{4}\left(g_{0}=0.101, g_{1}=0.093\right.$, derived from Ecolight simulations). The four pairs of $g_{0}$ and $g_{1}$ values are used to show that the IOP's shape issues are not a result of the choice of $g_{0}$ and $g_{1}$ values.

Based on previous studies [64,68], $a_{p h}(i)$ is parameterized from $a_{p h} 675(i)$ to describe the initial guess of $a_{p h}(\lambda)$,

$$
a_{p h}(\lambda, i)=a_{p h} 675(i)\left[B_{0}(\lambda)+\ln \left(a_{p h} 675(i)\right) \times B_{1}(\lambda)\right]
$$
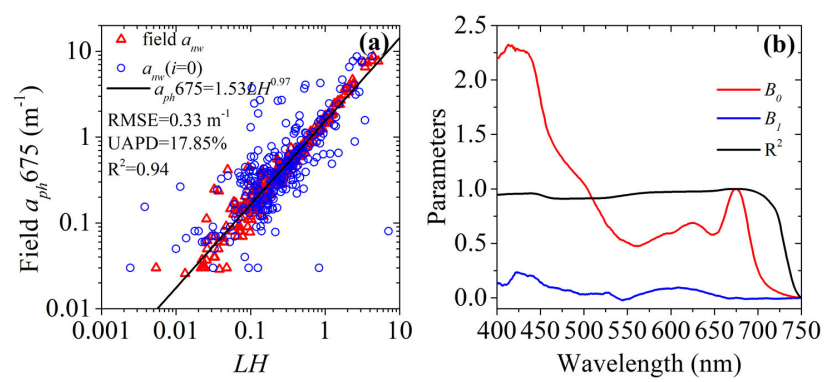

Fig. 5. (a) Comparisons between field-measured $a_{p h} 675$ and LH derived from field-measured $a_{n w}(\lambda)$ and $a_{n w}(\lambda, i=0)$, respectively. The black line is the equation fitted from field-measured $a_{n w}(\lambda)$. (b) Parameters $\left(B_{0}, B_{1}\right)$ and $\mathrm{R}^{2}$ of the relationship between the field-measured $a_{p h}(\lambda)$ and $a_{p h} 675$ in Eq. (14).

where $B_{0}(\lambda)$ and $B_{1}(\lambda)$ [Fig. 5(b)] are derived from the field $a_{p h} 675$ and field $a_{p h}(\lambda)$ at each wavelength using the least squares regression.

The $a_{d g}(\lambda, i)$ is obtained as the difference,

$$
a_{d g}(\lambda, i)=a_{n w}(\lambda, i)-a_{p h}(\lambda, i) .
$$

It follows that uncertainties in $a_{n w}(\lambda, i)$ and $a_{p h}(\lambda, i)$ are transferred into $a_{d g}(\lambda, i)$. By assuming that $a_{d g}(\lambda, i)$ follows an exponential function plus a constant, $a_{d g}(\lambda, i)$ is fitted to a new spectrum with three fitting parameters $\left(C_{0}, S_{d g}\right.$, and $\left.C_{1}\right)$, which were determined using a least squares regression with a cost function as

$\chi(i)^{2}=\sum_{j=1}^{\mathrm{N}}\left(a_{d g}\left(\lambda_{j}, i\right)-C_{0} \exp \left(-S_{d g}\left(\lambda_{j}-440\right)\right)-C_{1}\right)^{2}$,

where, $C_{0}$ and $C_{1}$ are limited to positive values, and $S_{d g}$ is limited in value from 0.005 to $0.013 \mathrm{~nm}^{-1}$ (based on our dataset). The wavelength range used $\left(\lambda_{1}-\lambda_{N}\right)$ is $400-550 \mathrm{~nm}$ and $730-750 \mathrm{~nm}$, respectively, to avoid the uncertainties induced from the initial $a_{n w}(\lambda)$. The fit to $a_{d g}(\lambda, i)$ with the minimum $\chi(i)^{2}$ is $a_{d g-f}(\lambda, i)$. 
The residual, $\Delta(\lambda, i)$, is computed as

$$
\Delta(\lambda, i)=a_{d g}(\lambda, i)-a_{d g-f}(\lambda, i) .
$$

If the average $\Delta(400-700, i)>0.01 \mathrm{~m}^{-1}$ (the assumed uncertainty in absorption), another iteration $(i=i+1)$ is performed after removing $\Delta(\lambda, i)$ from $a_{n w}(\lambda, i)$,

$$
a_{n w}(\lambda, i+1)=a_{n w}(\lambda, i)-\Delta(\lambda, i) .
$$

If the average $\Delta(400-700, i)<=0.01 \mathrm{~m}^{-1}$, the new $a_{p h}\left(\lambda, i_{\text {end }}\right)\left[a_{p h-n}(\lambda)\right]$ is derived from the new $a_{n w}\left(\lambda, i_{\text {end }}\right)$ $\left[a_{n w-n}(\lambda)\right]$ and fitted $a_{d g-f}\left(\lambda, i_{\text {end }}\right)$ in the final loop $\left(i=i_{\text {end }}\right)$,

$$
a_{p h-n}(\lambda)=a_{n w-n}(\lambda)-a_{d g-f}\left(\lambda, i_{\text {end }}\right) .
$$

Then, the $b_{b p-n}(\lambda)$ is recalculated,

$$
b_{b p-n}(\lambda)=\frac{u(\lambda) \times\left(a_{n w-n}(\lambda)+a_{w}(\lambda)\right)}{1-u(\lambda)}-b_{b w}(\lambda) .
$$

\section{B. Application of the Proposed Algorithm to OLCI Data}

We design the algorithm using the in situ hyperspectral $R_{r s}(\lambda)$ ranging from 400 to $720 \mathrm{~nm}$. For OLCI data, the model is similar but contains several changes. Due to the lack of a suitable OLCI band near $650 \mathrm{~nm}$ [needed to compute the LH(i) based on Eq. (12)], $a_{p h} 675(i)$ for OLCI data is derived using $a_{n w}(\lambda)$ at 665 and $674 \mathrm{~nm}$ following the method in QAA750 \{Eqs. (2)-(7) in Ref. [29]\},

$$
a_{p h}(674)=\frac{a_{n w}(674)-\varepsilon \times a_{n w}(665)}{\left(1-\varepsilon \times S_{1}\right)},
$$

where $S_{1}=0.839$ and $\varepsilon=0.882$.

The parameters in the function for $a_{p h} 675(i)$ and $a_{p h}(\lambda)$ [Eq. (14)] are derived from the field-measured $a_{p h}(\lambda)$, which is wavelength-averaged using the SRF of OLCI. In addition, due to the large uncertainties in OLCI-derived $R_{r s}$ at 400 and $412 \mathrm{~nm}, C_{0}, S_{d g}$, and $C_{1}$ in Eq. (16) are derived by fitting $a_{d g}(\lambda, i)$ at wavelengths $>412 \mathrm{~nm}$.

\section{Other IOP Inversion Models Used in This Study}

Two other IOP inversion algorithms, a nonlinear optimization method and a tuned LS2 model [69], were compared with the proposed algorithm in deriving $a_{n w}(\lambda)$ and $b_{b p}(\lambda)$ using the in situ data. The nonlinear optimization method (Appendix B.1) was built based on $[2,70]$ by decomposing the $a_{p h}(\lambda)$ into 12 Gaussian peaks. The LS2 model [69] was tuned by building a new lookup table using radiative-transfer simulations (Ecolight 5 [71]) of inland lakes in this study region and by tuning the empirical models for deriving downwelling diffuse attenuation coefficient, $K_{d}(\lambda)$, and scattering coefficient, $b(\lambda)$, to our in situ data. The input parameters for the tuned LS2 model (Appendix B.2) include $R_{r s}(\lambda)$, SPIM, and the sun zenith angle. Further details of the two models are described in Appendix B.

\section{Analysis of Uncertainties}

To evaluate the performance of the algorithms, the unbiased RMSE in relative percentage (URMSE, \%); the UAPD, \%;
RMSE; and bias were calculated to describe the differences between the field-measured data $\left(\mathrm{X}_{\mathrm{i}}\right)$ and the model-derived data $\left(\mathrm{Y}_{\mathrm{i}}\right)$. These parameters are defined as follows with $\mathrm{N}$ as the number of samples:

$$
\begin{gathered}
\text { URMSE }=\sqrt{\frac{1}{\mathrm{~N}} \sum_{i=1}^{N}\left(\frac{\mathrm{Y}_{\mathrm{i}}-\mathrm{X}_{\mathrm{i}}}{0.5\left(\mathrm{Y}_{\mathrm{i}}+\mathrm{X}_{\mathrm{i}}\right)}\right)^{2}} \times 100 \%, \\
\mathrm{UAPD}=\frac{1}{\mathrm{~N}} \sum_{i=1}^{\mathrm{N}} \frac{\left|\mathrm{Y}_{\mathrm{i}}-\mathrm{X}_{\mathrm{i}}\right|}{0.5\left(\mathrm{Y}_{\mathrm{i}}+\mathrm{X}_{\mathrm{i}}\right)} \times 100 \%, \\
\text { RMSE }=\sqrt{\frac{1}{\mathrm{~N}} \sum_{i=1}^{\mathrm{N}}\left(\mathrm{Y}_{\mathrm{i}}-\mathrm{X}_{\mathrm{i}}\right)^{2}}, \\
\text { Bias }=\frac{1}{\mathrm{~N}} \sum_{i=1}^{\mathrm{N}}\left(\mathrm{Y}_{\mathrm{i}}-\mathrm{X}_{\mathrm{i}}\right) .
\end{gathered}
$$

\section{RESULTS}

\section{A. Absorption Properties of the Lakes in the MLYHR Region}

The median $a_{n w}(\lambda)$ values do not have obvious absorption peaks in the blue part of the spectrum due to the dominance of $a_{d g}(\lambda)$ [Figs. 6(a)-6(c)]. The median $a_{d g}(\lambda)$ is approximately 3 to 4 times larger than the median $a_{p h}(\lambda)$ at wavelengths shorter than $550 \mathrm{~nm}$. For wavelengths longer than $550 \mathrm{~nm}$, the contribution of $a_{p h}(\lambda)$ to $a_{n w}(\lambda)$ increases at the expense of $a_{d g}(\lambda)$. The absorption peak of the $a_{p h}(\lambda)$ at approximately $675 \mathrm{~nm}$ [Fig. 6(d)] is a key feature to distinguish phytoplankton from
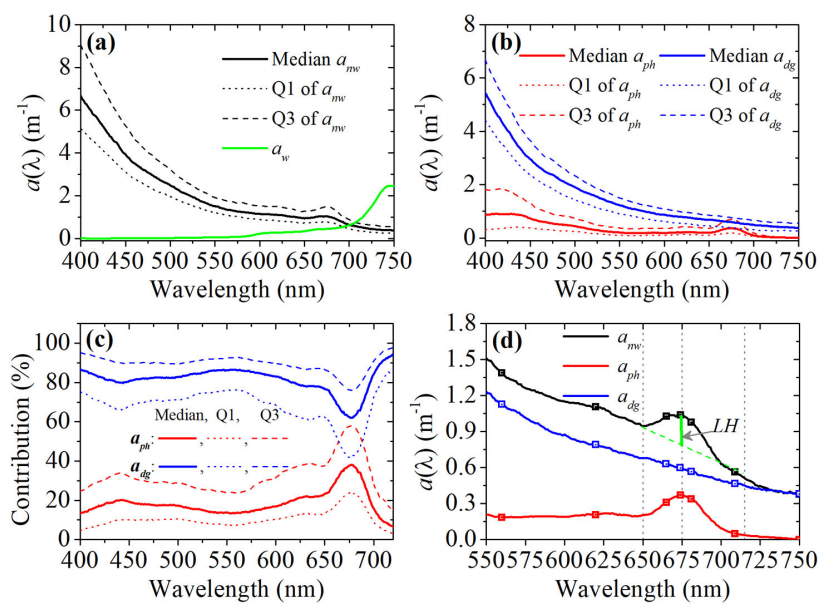

Fig. 6. (a) Statistics (Q1-median-Q3) of $a_{n w}(\lambda)$ and published $a_{w}(\lambda)$ [51]. (b) Statistics (Q1-median-Q3) of $a_{p h}(\lambda)$ and $a_{d g}(\lambda)$. (c) Q1-median-Q3 values of the contributions of $a_{p h}(\lambda)$ and $a_{d g}(\lambda)$ to $a_{n w}(\lambda)$. (d) Median values of $a_{n w}(\lambda), a_{p h}(\lambda)$, and $a_{d g}(\lambda)$ from $550 \mathrm{~nm}$ to $750 \mathrm{~nm}$, and the description of the absorption line height around $675 \mathrm{~nm}$ [LH, Eq. (12)]. "Q1" represents the middle value between the minimum and the median value of the dataset; "Q3" represents the middle value between the median and the maximum value of the dataset. 
NAP in turbid inland waters. Note that $a_{w}(\lambda)$ plays an increasing role in the NIR range and reaches $2.37 \mathrm{~m}^{-1}$ at $750 \mathrm{~nm}$ [51] [Fig. 6(a)].

\section{B. Algorithm Performance with In Situ Data}

1. Performance in Estimating $a_{n w}(\lambda)$ and $b_{b p}(\lambda)$

For the calibration dataset, QAA750-ap and the proposed model exhibit better performance than the nonlinear optimization method and tuned LS2 model in deriving $a_{n w}(\lambda)$ $(\mathrm{N}=249)$, and the proposed model performs better than QAA750-ap in the red wavelengths (Figs. 7, 8). The nonlinear optimization method and the tuned LS2 model tend to provide large relative errors and have significant underestimation of $a_{n w}(\lambda)$. Therefore, the $a_{n w}(\lambda)$ derived from QAA750-ap is a better choice for the initial value in the proposed model. $a_{n w}(\lambda)$ derived from the novel algorithm has a mean URMSE of $39.45 \%$ and UAPD of $34.86 \%$ from 400 to $720 \mathrm{~nm}$. The mean RMSE of $a_{n w}(\lambda)$ is $2.06 \mathrm{~m}^{-1}$ from 400 to $500 \mathrm{~nm}$ and decreases to $0.77 \mathrm{~m}^{-1}$ from 500 to $720 \mathrm{~nm} . a_{n w}(\lambda)$ derived from the new model shows slightly better performance for wavelengths $>600 \mathrm{~nm}$ by removing some of the residuals in the QAA750-ap-derived $a_{n w}(\lambda)$. The four models exhibit
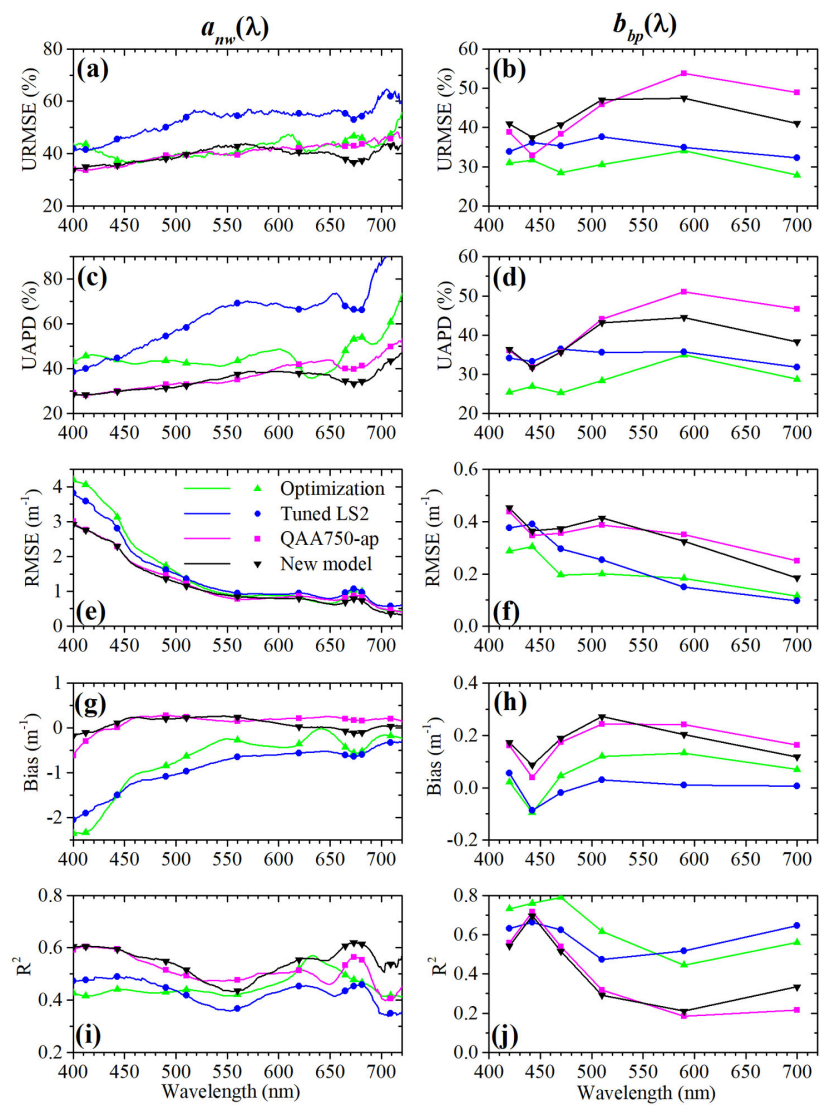

Fig. 7. Uncertainties of the four models (nonlinear optimization method, tuned LS2 model, QAA750-ap, and the proposed model) in deriving $a_{n w}(\lambda)\left(\mathrm{N}=249\right.$, the left panel) and $b_{b p}(\lambda)(\mathrm{N}=112$, the right panel) compared with the in situ calibration data. The markers in the left panel represent the OLCI bands. Six bands (420, 442, 470, 510,590 , and $700 \mathrm{~nm}$ ) of in situ $b_{b p}(\lambda)$ data were used. Note that the number of in situ SPIM values, which is needed in the tuned LS2 model, is 249 , and the number of in situ $b_{b p}(\lambda)$ values is 112 .
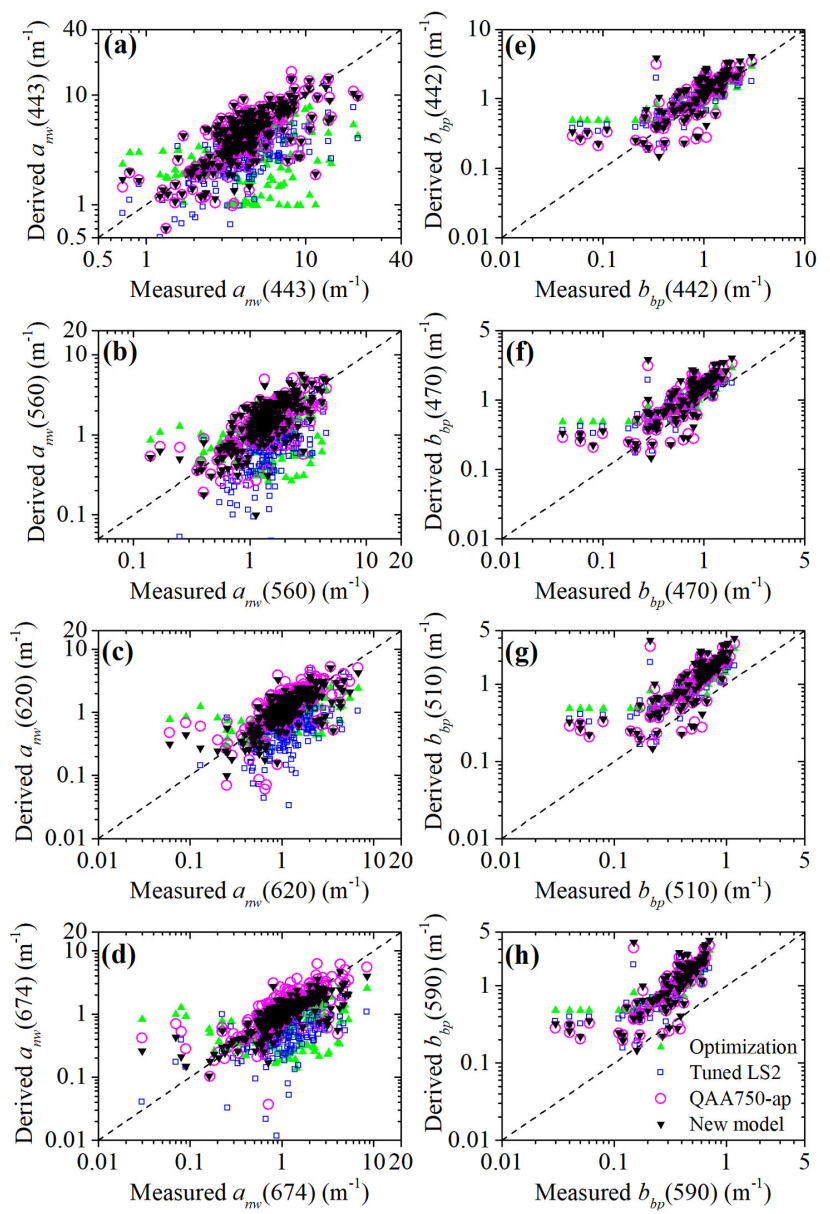

Fig. 8. Comparisons between field-measured data and the models (the nonlinear optimization method, tuned LS2 model, QAA750-ap, and the proposed new model) deriving $a_{n w}(\lambda)$ at 443, 560, 620, and $674 \mathrm{~nm}$ and $b_{b p}(\lambda)$ at $442,470,510$, and $590 \mathrm{~nm}$ [four bands of the in situ $\left.b_{b p}(\lambda)\right]$.

similar performance in estimating $b_{b p}(\lambda)(\mathrm{N}=112)$ of the first three bands $(420,442$, and $470 \mathrm{~nm})$, but overestimate $b_{b p}(\lambda)$ compared to the in situ $b_{b p}(\lambda)$ at the longer wavelengths [Figs. 8(e)-8(h)]. Note that the proposed model also has improved performance in deriving $b_{b p}(590)$ and $b_{b p}(700)$ than the updated QAA750-ap (but it is worse than the tuned LS2 model and optimization method).

\section{Performance in Estimating $a_{p h}(\lambda)$ and $a_{d g}(\lambda)$}

Performance of the proposed algorithm in deriving $a_{n w}(\lambda)$, $a_{p h}(\lambda)$, and $a_{d g}(\lambda)$ from the calibration data $(\mathrm{N}=285)$ and validation data $(\mathrm{N}=57)$ is presented in Fig. 9. Compared with $a_{n w}(\lambda)$, the uncertainties in the $a_{p h}(\lambda)$ and $a_{d g}(\lambda)$ are higher with an underestimation of $a_{p h}(\lambda)$ and an overestimation of $a_{d g}(\lambda)$, especially for the wavelengths from 400 to $500 \mathrm{~nm}$. The algorithm performs better in deriving $a_{p h}(\lambda)$ at wavelengths $>500 \mathrm{~nm}$ with a mean UAPD of $55.22 \%$ and RMSE of $0.44 \mathrm{~m}^{-1}$, than for the wavelengths ranging from 400 to $500 \mathrm{~nm}$ with a mean UAPD of $61.85 \%$ and RMSE of $1.35 \mathrm{~m}^{-1}$. 

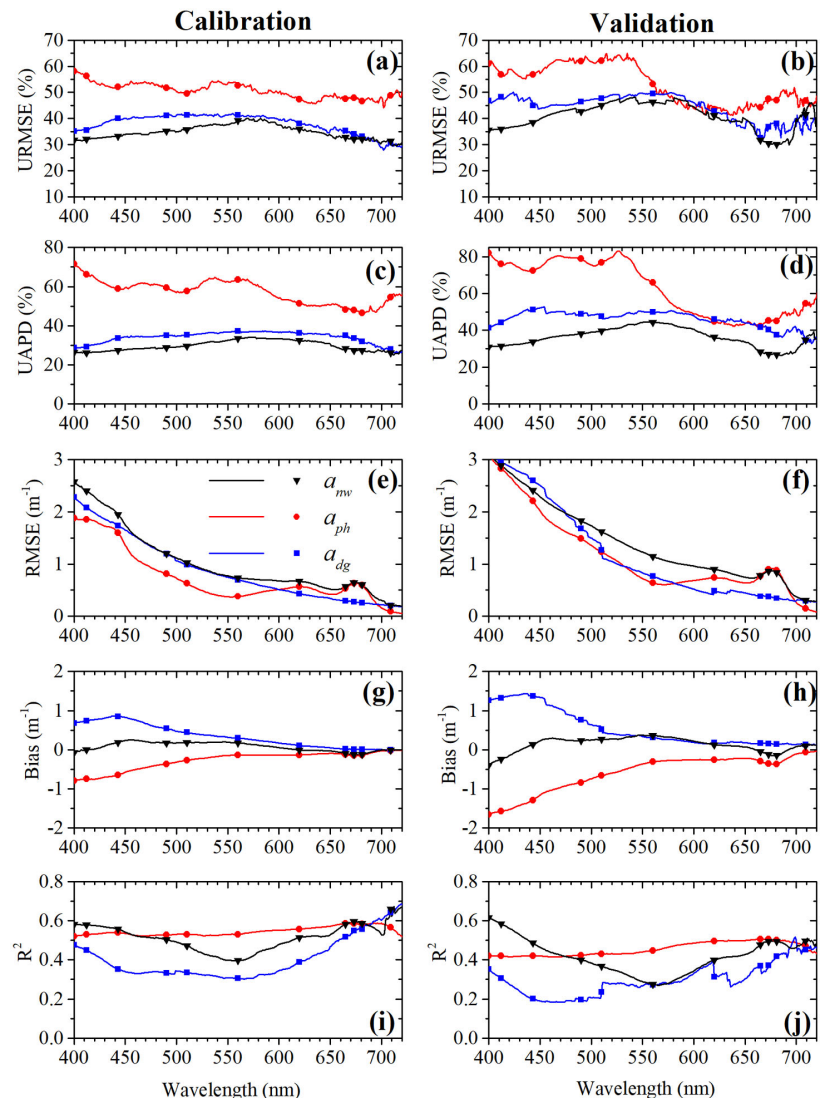

Fig. 9. Performance of the proposed model in deriving $a_{n w}(\lambda)$, $a_{p h}(\lambda)$, and $a_{d g}(\lambda)$ using in situ calibration data $(\mathrm{N}=285)$ and validation data $(\mathrm{N}=57)$. The markers represent the OLCI bands.
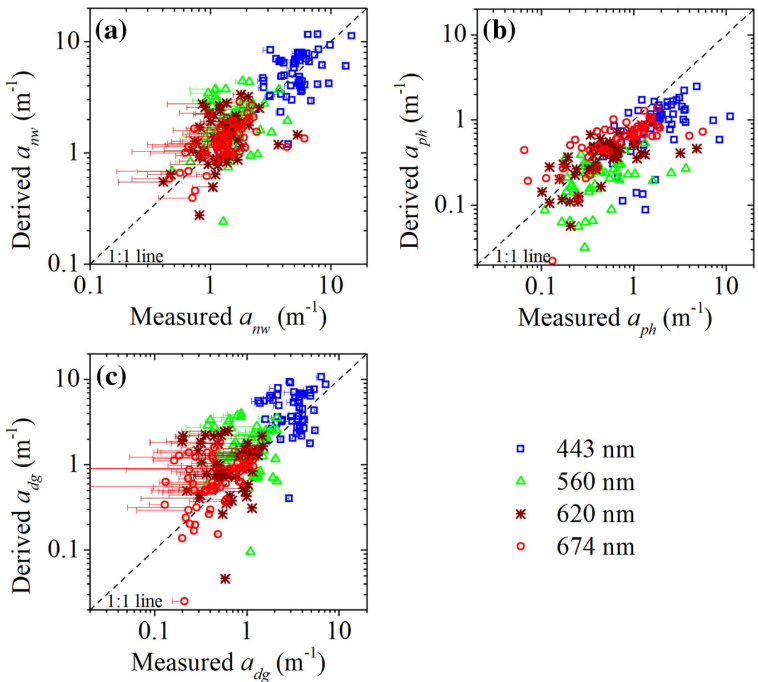

- $\quad 443 \mathrm{~nm}$
$\Delta \quad 560 \mathrm{~nm}$
* $620 \mathrm{~nm}$
॰ $674 \mathrm{~nm}$

Fig. 10. Comparisons between measured and model-derived (a) $a_{n w}(\lambda)$, (b) $a_{p h}(\lambda)$, and (c) $a_{d g}(\lambda)$ at $443,560,620$, and $674 \mathrm{~nm}$ $(\mathrm{N}=57)$. Note that the error bars of the measured $a_{n w}(\lambda)$ and the measured $a_{d g}(\lambda)$ are based on the uncertainties in the estimated $a_{p}(750)$.

In addition, the performance of the algorithm for the in situ validation data shows similar results with those for the calibration data. For instance, $a_{p h}(\lambda)$ has a mean RMSE of $0.71 \mathrm{~m}^{-1}$
Table 2. Uncertainties [UAPD (\%), RMSE $\left(\mathrm{m}^{-1}\right)$, and $\left.R^{2}\right]$ of $a_{n w}(\lambda), a_{p h}(\lambda)$, and $a_{d g}(\lambda)$ for Validation Data $(\mathrm{N}=57)$ at $\mathrm{OLCl}$ Bands

\begin{tabular}{|c|c|c|c|c|c|c|c|c|c|}
\hline \multirow[b]{2}{*}{ Band (nm) } & \multicolumn{3}{|c|}{ UAPD (\%) } & \multicolumn{3}{|c|}{$\operatorname{RMSE}\left(\mathbf{m}^{-} \mathbf{1}\right)$} & \multicolumn{3}{|c|}{$R^{2}$} \\
\hline & $a_{n w}$ & $a_{p b}$ & $a_{d g}$ & $a_{n w}$ & $a_{p b}$ & $a_{d g}$ & $a_{n w}$ & $a_{p h}$ & $a_{d g}$ \\
\hline 400 & 31.00 & 81.99 & 41.35 & 3.11 & 3.08 & 3.10 & 0.62 & 0.42 & 0.35 \\
\hline 412 & 31.39 & 75.92 & 44.25 & 2.88 & 2.83 & 2.96 & 0.58 & 0.42 & 0.31 \\
\hline 443 & 33.80 & 72.51 & 51.20 & 2.42 & 2.21 & 2.60 & 0.49 & 0.42 & 0.20 \\
\hline 490 & 38.19 & 78.87 & 48.93 & 1.83 & 1.49 & 1.68 & 0.40 & 0.42 & 0.20 \\
\hline 510 & 39.78 & 76.86 & 47.61 & 1.62 & 1.23 & 1.27 & 0.37 & 0.43 & 0.24 \\
\hline 560 & 44.46 & 65.89 & 50.04 & 1.15 & 0.64 & 0.76 & 0.27 & 0.45 & 0.27 \\
\hline 620 & 36.28 & 44.84 & 46.07 & 0.90 & 0.74 & 0.49 & 0.40 & 0.50 & 0.31 \\
\hline 665 & 28.31 & 42.16 & 41.66 & 0.78 & 0.77 & 0.38 & 0.48 & 0.50 & 0.37 \\
\hline 673 & 27.06 & 45.26 & 40.31 & 0.86 & 0.90 & 0.37 & 0.49 & 0.51 & 0.37 \\
\hline 681 & 26.91 & 45.03 & 37.41 & 0.84 & 0.88 & 0.34 & 0.49 & 0.50 & 0.42 \\
\hline 709 & 34.74 & 54.47 & 34.63 & 0.30 & 0.15 & 0.29 & 0.50 & 0.47 & 0.45 \\
\hline
\end{tabular}

and a mean bias of $-0.33 \mathrm{~m}^{-1}$ from 500 to $720 \mathrm{~nm}$, compared to a mean RMSE of $2.10 \mathrm{~m}^{-1}$ and a mean bias of $-1.19 \mathrm{~m}^{-1}$ from 400 to $500 \mathrm{~nm}$. Comparisons between the measured and model-derived $a_{n w}(\lambda), a_{p h}(\lambda)$, and $a_{d g}(\lambda)$ at $443,560,620$, and $674 \mathrm{~nm}$, respectively, show that $a_{n w}(\lambda)$ performs well, but $a_{p h}(443)$ is underestimated (Fig. 10, Table 2). Overall, the results indicate that the proposed algorithm performs better in the longer wavelengths ranging from 500 to $720 \mathrm{~nm}$, and is an improvement on the other algorithms presented for the inversion of absorption coefficients.

\section{Algorithm Performance with the OLCI Satellite Data}

\section{Validation Using Matchup Pairs}

The proposed model is applied to the OLCI satellite data and validated using matchup pairs of field- and OLCI-derived $a_{n w}(\lambda), a_{p h}(\lambda)$, and $a_{d g}(\lambda)(\mathrm{N}=57)$ (Fig. 11). $a_{n w}(\lambda)$ is overestimated over the 11 OLCI bands from 400 to $709 \mathrm{~nm}$ with a mean $\mathrm{UAPD}=48.67 \%$, RMSE $=1.65 \mathrm{~m}^{-1}$, and bias $=0.99 \mathrm{~m}^{-1} \cdot a_{p h}(\lambda)$ shows slightly better performance $(\mathrm{URMSE}=43.90 \%)$ than $a_{n w}(\lambda)(\mathrm{URMSE}=52.32 \%)$ and $a_{d g}(\lambda)$ (URMSE $\left.=61.79 \%\right)$. The mean RMSEs of $a_{p h}(\lambda)$ for the first four bands (RMSE $=0.97 \mathrm{~m}^{-1}$ ) are larger than those of the bands from of 500 to $720 \mathrm{~nm}\left(\mathrm{RMSE}=0.42 \mathrm{~m}^{-1}\right)$. This algorithm results in improved accuracy over the first 11 bands of the OLCI satellite data compared to our previous model [29].

\section{Spatial Distribution of Absorption Coefficients}

The proposed algorithm is applied to the OLCI-derived $R_{r s}(\lambda)$ to map the spatial pattern of absorption coefficients of Lake Taihu on December 08, 2016 (Fig. 12). Three sites (S1-S3) representing different optical properties are selected to illustrate the results of the model. Note that the high value of the $R_{r s}(400)$ indicates the failure of atmospheric corrections in this band, and the floating scum (green areas in the quick scene of $R_{r s}$ ) is masked due to the failure of atmospheric correction. Compared with the $R_{r s}(\lambda)$ of $\mathrm{S} 1, \mathrm{~S} 2$ has higher values of $R_{r s}(\lambda)$ but is featureless at approximately $675 \mathrm{~nm}$, which is in accordance 

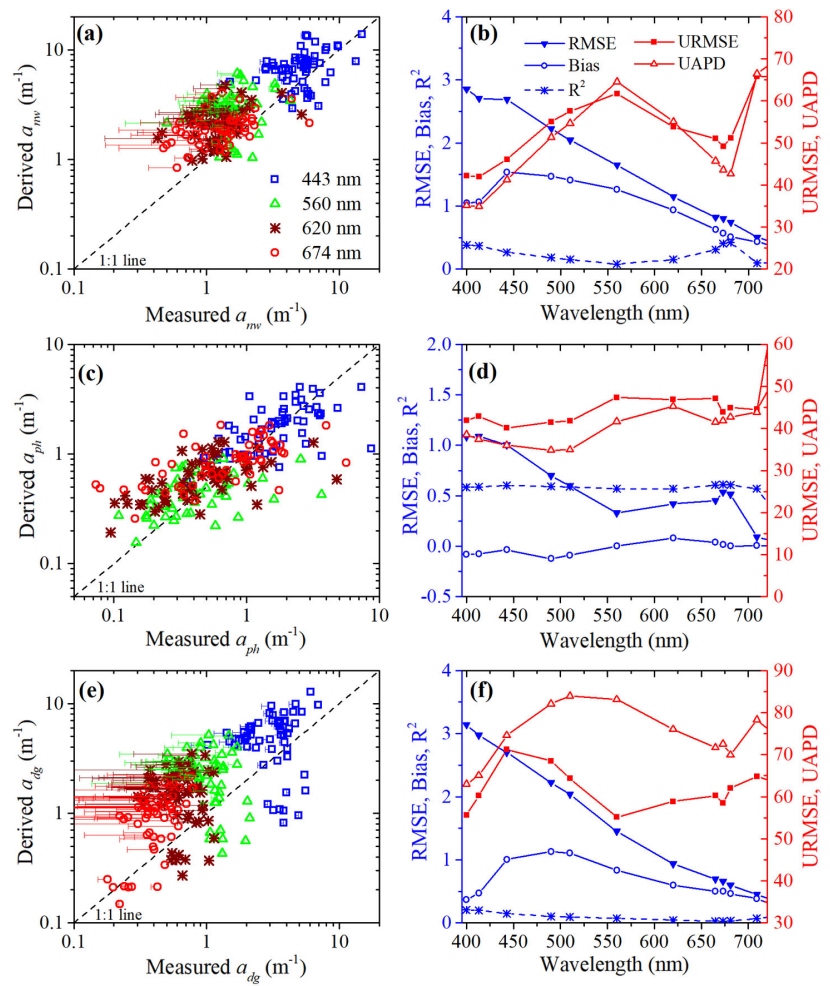

Fig. 11. Validation of the proposed algorithm for estimating (a), (b) $a_{n w}(\lambda),(\mathrm{c}),(\mathrm{d}) a_{p h}(\lambda)$, and (e), (f) $a_{d g}(\lambda)$ using matchup pairs between field-measured and OLCI-derived data. Comparisons of measured and model-derived (a) $a_{n w}(\lambda)$, (c) $a_{p h}(\lambda)$, and (e) $a_{d g}(\lambda)$ at 443 , 560,620 , and $674 \mathrm{~nm}$, respectively. Statistical results of (b) $a_{n w}(\lambda)$, (d) $a_{p h}(\lambda)$, and (f) $a_{d g}(\lambda)$ for 11 bands of OLCI data. Note that the error bars of measured $a_{n w}(\lambda)$ and measured $a_{d g}(\lambda)$ are based on the uncertainties in the estimated $a_{p}(750)$.

with the lower value of $a_{p h}(\lambda)$ in S2. S3 has higher values of $R_{r s}(\lambda)$ than $S 1$ with similar characteristics around $675 \mathrm{~nm}$, indicating a higher content of inorganic suspended particles. This result is consistent with the higher $a_{d g}(\lambda)$ of $S 3$ than that of $S 1$ [Fig. 12(d)]. The areas around $S 1$ have high values at $a_{p h}(510)$ and $a_{p h}(674)$, while $a_{d g}(\lambda)$ in this area does not show high values and large spatial variations; both $a_{p h}$ and $a_{d g}$ are observed with high values in the areas around S3. Overall, the high $a_{n w}$ in the three bays in the northern part of Lake Taihu is caused by the high $a_{p h}$, and the southern part of Lake Taihu is mainly dominated by a high $a_{d g}$, except for some parts where algal blooms are present.

\section{DISCUSSION}

\section{A. Uncertainties of $a_{p}(\lambda)$ Measured with T-Mode}

The NIR null point correction of particulate absorption was used to correct for scattering offsets in the T-mode. However, the NIR null point correction removes the NAP absorption in the NIR band, and leads to the underestimation of $a_{p}(\lambda)$ across the spectrum in coastal or mineral-rich waters [40,72]. A linear function (slope 0.988 , intercept -0.0004 ) was designed to correct T-mode absorption measurements and to make them consistent with NAP absorptions measured by a pointsource integrating cavity absorption meter (PSICAM) from $362-726 \mathrm{~nm}$ [72]. We attempted to estimate $a_{p}(750)$ from the exponential function of $a_{d}(\lambda)$ and the calculating of the spectral slope of $a_{d}(\lambda)\left(S_{d}\right)$; however, this goal was not achieved because the null assumption for NIR also changed the values of $S_{d}$. The present study provides a method to estimate $a_{p}(750)$ from Chla and SPM, or from $R_{r s}(\lambda)$, based on the proportion of phytoplankton and NAP in SPM. In this way, the historical data measured using the T-mode can be corrected by adding estimated $a_{p}(750)$ as a baseline. Since QAA750 was built and validated using field-measured $a_{p}(\lambda)$ based on the null NIR assumption, we updated it by considering $a_{p}$ (750) in this study.

After corrections, the mean $a_{p}^{*}(443)$ (mass-specific absorption coefficients of particulates, $\left.=a_{p}(443) / \mathrm{SPM}\right)$ and $a_{d}^{*}(443)$ (mass-specific absorption coefficients of NAP, $\left.=a_{d}(443) / \mathrm{SPM}\right)$ of the measured data were $0.085 \pm 0.052$ and $0.050 \pm 0.027 \mathrm{~m}^{2} \mathrm{~g}^{-1}$. It has been reported that $a_{p}(\lambda)$ at the blue wavelengths varied from $0.05 \mathrm{~m}^{2} \mathrm{~g}^{-1}$ for organicdominated soil dust to $0.1-0.5 \mathrm{~m}^{2} \mathrm{~g}^{-1}$ for mineral-dominated samples [73]. The mean $a_{d}^{*}(443)$ in this study is higher than the mean $a_{d}^{*}(443)\left(0.031 \mathrm{~m}^{2} \mathrm{~g}^{-1}\right)$ observed in the coastal waters around Europe, whose $a_{d}(\lambda)$ was also obtained by subtracting the measured values of $a_{d}$ (750) [74]. Moreover, this result indicates that the null NIR assumption is significant in the red and NIR bands; for instance, the mean $a_{d}^{*}(650)$ values of the uncorrected and corrected data are $0.004 \pm 0.002$ and $0.014 \pm 0.005 \mathrm{~m}^{2} \mathrm{~g}^{-1}$, respectively. The mean $a_{d}^{*}(650)$ $\left(0.014 \pm 0.005 \mathrm{~m}^{2} \mathrm{~g}^{-1}\right)$ and $a_{d}^{*}(750)\left(0.010 \pm 0.004 \mathrm{~m}^{2} \mathrm{~g}^{-1}\right)$ of the corrected data were comparable with those of the results in the German Bight $\left(0.013 \pm 0.003,0.009 \pm 0.003 \mathrm{~m}^{2} \mathrm{~g}^{-1}\right)$ and were lower than those of Elbe River $(0.018 \pm 0.001$, $0.014 \pm 0.001 \mathrm{~m}^{2} \mathrm{~g}^{-1}$ ) as shown in the study of Röttgers et al. [40]. Note that the mean value of $a_{d}^{*}(750)$ from the Elbe River is used in this study; in fact, $a_{d}^{*}(750)$ is related to particle compositions and particle size distributions [73,74]. A trend towards lower mass-specific absorption coefficients of particulates in clearer waters was observed [40]. Low values of $a_{d}^{*}(\lambda)$ were reported for noncolored minerals and clear waters, and high values were related to colored minerals and small particles $[40,73,74]$.

The advantages of the integrating sphere approach (IS-mode) have been demonstrated with high accuracy and simple measurement protocol [75,76]. It reported that some signal can still be detected in the IS-mode when the phytoplankton content is high [40]. Here, we assume that the phytoplankton absorption at $750 \mathrm{~nm}$ is negligible after masking the floating scum. We recommend that the IS-mode should be used to measure the absorption coefficients in future studies, and that additional studies take place to validate this method in estimating $a_{p}(750)$ for $a_{p}(\lambda)$ that were measured using the T-mode.

\section{B. Performance of the Proposed Algorithm}

\section{Comparison with Other Models}

$a_{n w}(\lambda)$ derived from the nonlinear optimization method, tuned LS2 model, QAA750-ap, and the proposed model had large uncertainties in the short wavelengths, which induced uncertainties into the following steps. A previous study [16] showed 


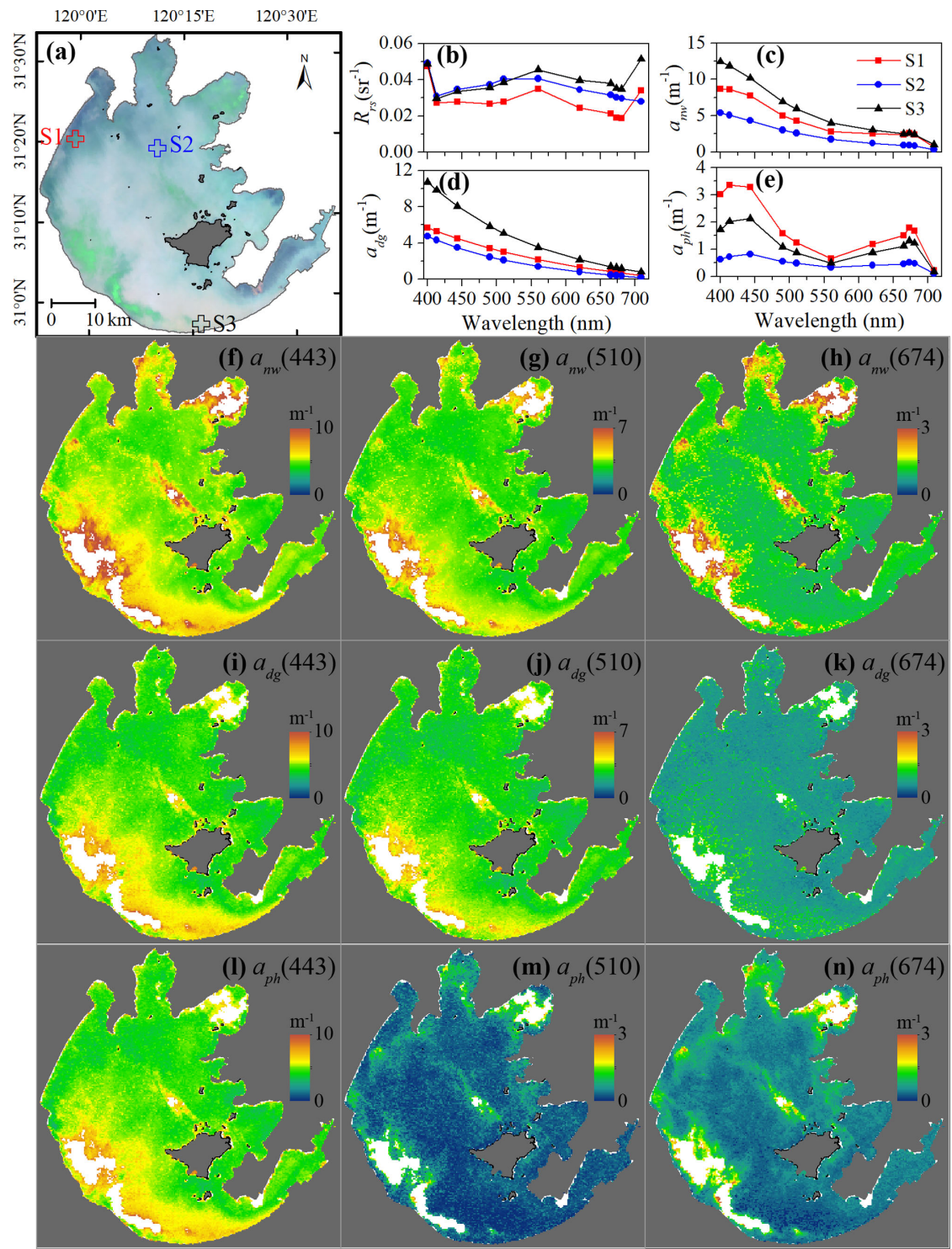

Fig. 12. Example of OLCI-derived absorption coefficients for Lake Taihu on December 08, 2016: (a) RGB image (R, Band 10; G, Band 6; and B, Band 3); (b)-(e) OLCI-derived $R_{r s}(\lambda), a_{n w}(\lambda), a_{d g}(\lambda), a_{p h}(\lambda)$ from three sites (S1-S3), representing different bio-optical properties. Spatial distributions of (f) $-(\mathrm{h}) a_{n w}(\lambda),(\mathrm{i}-\mathrm{k}) a_{p h}(\lambda)$, and (i) $-(\mathrm{n}) a_{d g}(\lambda)$ at 443,510 , and $674 \mathrm{~nm}$, respectively.

similar large errors with an average RMSE of $1.77 \mathrm{~m}^{-1}$ when retrieving $a(\lambda)$ for wavelengths from 400 to $500 \mathrm{~nm}$ in CDOMdominated waters. However, it was reported that $a_{n w}(\lambda)$ was not well estimated for the long wavelengths $(>550 \mathrm{~nm})$ in open ocean waters due to the lower contribution of $a_{n w}(\lambda)$ to $a(\lambda)$ than that of $a_{w}(\lambda)$ at these wavelengths [69].

The LS2 model performed well in a broad range of oceanic and coastal marine waters [69]; however, the tuned LS2 model did not perform well in this study, even though a new lookup table was built using 4212 Ecolight simulations. One possible reason is that one set of specific inherent optical properties (SIOPs) was used in our simulation data; in fact, the SIOPs varied greatly in the optically complex inland waters. Therefore, a robust lookup table built using simulation data with a large range of SIOPs and acceptable optical closure is likely necessary when inverting IOPs using this method in optically turbid waters. In addition, broad limits of variables are needed in the nonlinear optimization model due to the large range and variability of bio-optical properties in inland waters.

In the development of IOP inversion models, it is relatively easy to derive the total absorption and backscattering coefficients and the absorption coefficients of water components that dominate the water [22]. Relative RMSE values of $a_{p h}$ in the visible range between $25 \%$ and $31 \%$ were obtained in phytoplankton-dominated waters [15,77], but the uncertainties in estimating $a_{p h}$ would be larger in NAP- and CDOMdominated waters [16]. QAA has also been reparameterized in CDOM-dominated waters using a normalized phytoplankton absorption coefficient to obtain improved performance for $a_{p h}$ [16]. However, the scatter plots of $a_{p h}$ at specific wavelengths did not show satisfactory results in the study of Ogashawara et al. [16], which also demonstrated the difficulty of retrieving 
$a_{p h}$ from waters dominated by CDOM and NAP. On the other hand, phytoplankton was often the most important factor causing uncertainties into the CDOM remote sensing inversion in CDOM-dominated inland waters [78].

\section{Performance in Retrieving $a_{p h}(\lambda)$ in Turbid Waters}

When partitioning $a(\lambda)$ into its components, most algorithms assume an $a_{p h}(\lambda)$ spectral shape or normalized $a_{p h}(\lambda)$ spectral features from Chla [23], $R_{r s}$ [18], and the contribution of phytoplankton groups [79] based on bio-optical parameters from specific regions or in situ measurements taken with specific instruments. A challenge for estimating $a_{p h}(\lambda)$ in turbid waters is to obtain a reasonable spectral shape for $a_{p h}(\lambda)$. For the nonlinear optimization method and QAA750, $a_{p h}(\lambda)$ showed obvious overestimation in the blue and green bands, which did not present reasonable $a_{p h}(\lambda)$ values (data not shown), especially in the blue range, due to the large contribution of $a_{d g}(\lambda)$. In our previous study, $a_{p h}(443)$ was derived from OLCI-derived $a_{p h}(674)$ according to their relationship in QAA750 [29]. If $a_{p h}(674)$ and the spectral shape of $a_{p h}(\lambda)$ derived from the measured data were used to model $a_{p h}(\lambda)$, the normalization of the derived $a_{p h}(\lambda)$ would be the same.

In this study, the relationship between the measured $a_{p h} 675$ and $a_{p h}(\lambda)$ was used as a first guess to parameterize the initial $a_{p h}(\lambda)$ in the iterative model to obtain a reasonable $a_{p h}(\lambda)$ spectrum. Moreover, the use of the spectral shape of $a_{p h}(\lambda)$ computed from $a_{p h} 675$ can also be a source of error in the estimation of $a_{p h}(\lambda)$ [16]. We attempted to classify the parameters in Eq. (14) according to the value of $a_{p h} 675$, whereas there was little difference from using one set of parameters in Eq. (14). The parameterization of $a_{p h}(\lambda)$ or normalized $a_{p h}(\lambda)$ should be improved in inland-water remote sensing because of the variations in phytoplankton groups and compositions.

As $a_{d g}(\lambda)$ had a high contribution to $a_{n w}(\lambda)$ in the short wavelengths, a small relative error in $a_{n w}(\lambda)$ and $a_{d g}(\lambda)$ would introduce large variations in $a_{p h}(\lambda)$ [mean $a_{p h}(443) / a_{n w}(443)$ is about 20\%]. This phenomenon is similar to studies in CDOM-dominated waters: the spectral variation due to errors of $a_{p h}(\lambda)$ can be related to the residual interference from CDOM in the short wavelengths, and errors of $a_{p h}(\lambda)$ were lower at longer wavelengths [16]. Thus, we suggest that longer wavelengths $(>500 \mathrm{~nm})$ should be used in turbid waters to effectively estimate $a_{p h}(\lambda)$.

\section{Iterative Method can Remove Part of the Residuals}

Performance of the proposed model on calibration data was evaluated using measured $a_{n w}(\lambda)$ as input parameters. The result indicates that the accuracy of $a_{d g}(\lambda)$ improved with a mean URMSE $24.7 \%$, UAPD $18.3 \%$, and RMSE $0.68 \mathrm{~m}^{-1}$. $a_{p h}(\lambda)$ derived from the measured $a_{n w}(\lambda)$ shows slightly better performance with a mean URMSE $47.4 \%$, UAPD $46.9 \%$, and RMSE $0.75 \mathrm{~m}^{-1}$. Generally, this obvious improvement for $a_{d g}(\lambda)$ indicates that model-derived $a_{n w}(\lambda)$ induces larger uncertainties to $a_{d g}(\lambda)$ than to $a_{p h}(\lambda)$.

The iterative method can remove part of the residuals caused by the gap between the field data and the $R_{r s}(\lambda)$ model in the red range; however, the uncertainties from the model-derived
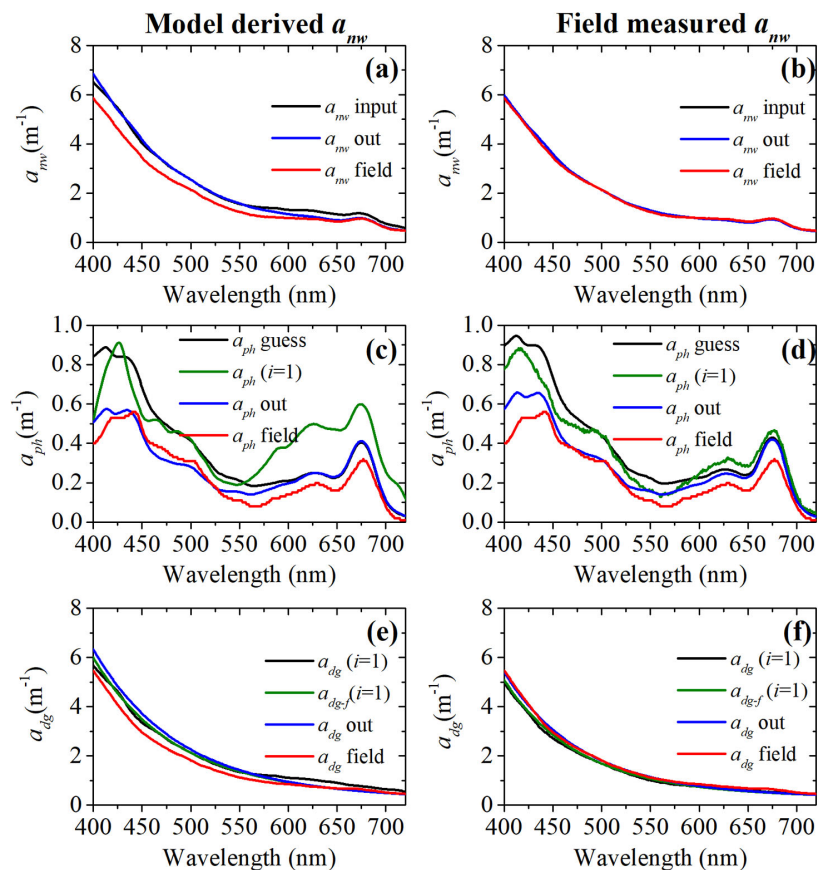

Fig. 13. Example to present the model-derived (a), (b) $a_{n w}(\lambda)$, (c), (d) $a_{p h}(\lambda)$, and (e), (f) $a_{d g}(\lambda)$ : the left panel shows the results of the proposed model, and the right panel shows the results of the proposed model with the field-measured $a_{n w}(\lambda)$ as input. The green lines represent the results with $i=1$.

$a_{n w}(\lambda)$ in the short wavelengths are not removed (Fig. 13). That is, if the model-derived $a_{n w}(\lambda)$ has large errors in the blue and green range, this iterative model cannot perform better in deriving $a_{p h}(\lambda)$ and $a_{d g}(\lambda)$. For example, when the input $a_{n w}(\lambda)$ had a difference from field-measured $a_{n w}(\lambda)$, the model-derived $a_{n w}(\lambda)$ still had uncertainties for the 400 to $600 \mathrm{~nm}$ range, but the residuals in the red wavelengths decreased [Fig. 13(a)]. Compared with the case of field-measured $a_{n w}(\lambda)$ as input [Fig. 13(d)], if we do not use the iterative method to remove the residuals, the $a_{p h}(\lambda)\left[a_{p h}(i=1)\right.$ in Fig. 13(c)] would have obvious overestimation for wavelengths $>550 \mathrm{~nm}$.

\section{Limitations of the Proposed Model}

Based on the similarity in the spectral shapes of $a_{d}(\lambda)$ and $a_{g}(\lambda)$, the absorption coefficients of NAP and CDOM were merged into $a_{d g}(\lambda)$. Many approaches for partitioning $a(\lambda)$ into $a_{p h}(\lambda)$ and $a_{d g}(\lambda)$ assumed an exponential shape for $a_{d g}[18,22,23]$. It has been stated that $a_{d g}(\lambda)$ has limitations when linking IOPs to biogeochemical parameters due to the different origins of NAP and CDOM [22]. However, to derive the $a_{p h}(\lambda)$ more accurately, a two-component partitioning $\left[a_{p h}(\lambda)\right.$ and $\left.a_{d g}(\lambda)\right]$ model is used in this study. Note that there are also methods designed to separate $a_{d g}(\lambda)$ into $a_{d}(\lambda)$ and $a_{g}(\lambda)$ [80,81], which can be evaluated and used to separate $a_{d g}(\lambda)$ if necessary.

The proposed algorithm was also applied to the $R_{r s}$ of the OLCI satellite images. Previous studies evaluated the performance of the atmospheric-corrected $R_{r s}$ for the OLCI images over the lakes in the study region $[29,60]$. The weak performance of the atmospheric correction also adds uncertainties in the blue range. In addition, the method of computing $a_{p h} 675$ in 
QAA750 is used in this study due to the lack of a band around $650 \mathrm{~nm}$ in the OLCI data, indicating the difficulty of using this model with satellite data that do not have enough bands in the red and NIR wavelengths. Recently, a semianalytical model was built to derive the absorption coefficients of the water components from Landsat 8 reflectance in coastal waters by calculating a virtual $R_{r s}(412)$ [82]. Unfortunately, the large uncertainties associated with the atmospheric correction in the blue bands in optically complex waters [83] make it much more difficult to apply this algorithm to satellite data with high spatial resolution but with fewer spectral bands [e.g., Landsat $8 \backslash$ Operational Land Imager (OLI)].

\section{CONCLUSION}

For the particulate absorption data measured with the T-mode, $a_{p}(750)$ was estimated from Chla and SPM to correct the uncertainty associated with the NIR null correction. Based on the bio-optical properties of the lakes in the MLYHR basin region, a novel iterative inversion algorithm for estimating IOPs from $R_{r s}(\lambda)$ was built for turbid and eutrophic lakes. In the proposed model, the initial $a_{n w}(\lambda)$ is first derived from QAA750-ap, which is improved from QAA750 by estimating the $a_{p}(750)$ from the $R_{r s}(\lambda) . a_{n w}(\lambda)$ is then decomposed into the $a_{p h}(\lambda)$ and $a_{d g}(\lambda)$ after removing some of the residuals of the input $a_{n w}(\lambda)$ values in the red range. The proposed algorithm performed well in estimating $a_{p h}(\lambda)$ and $a_{d g}(\lambda)$, especially for wavelengths $>500 \mathrm{~nm}$, and was validated using matchup pairs of field-measured and OLCI-derived absorption coefficients. The spatial distribution of the absorption coefficients of Lake Taihu is mapped using Sentinel-3A/OLCI satellite data as an example, and displays reasonable spatial distributions. Overall, the proposed model provides better estimation of phytoplankton absorption in turbid waters than any other existing approaches we have applied. Users who are interested in applying this model to their region should first optimize the model based on in situ data in a manner similar to what was used in our approach.

\section{APPENDIX A: CORRECTION OF THE IN SITU PARTICULATE ABSORPTION DATA}

The largest uncertainty in $a_{p}(\lambda)$ measured using the T-mode approach arises from an unknown level of absorption in the NIR, and is caused by the fact that NAP absorption is nonzero for those wavelengths [39]. To estimate $a_{p}(750)$, we use the following approach: $f r$ is defined as the ratio of suspended particulate matter from phytoplankton $\left(\mathrm{SPM}_{p h}\right)$ to the total suspended particulate matter of NAP $\left(\mathrm{SPM}_{d}\right)$ and phytoplankton, which equals to SPM,

$$
f r=\frac{\mathrm{SPM}_{p h}}{\mathrm{SPM}_{d}+\mathrm{SPM}_{p h}}=\frac{\mathrm{SPM}_{p h}}{\mathrm{SPM}} .
$$

$a_{p}(750)$ is derived from $f r$, the mass-specific absorption coefficient of phytoplankton and NAP at $750 \mathrm{~nm}$, and SPM,

$$
\begin{aligned}
a_{p}(750)= & f r \times a_{p h}^{*}(750) \times \mathrm{SPM} \\
& +(1-f r) \times a_{d}^{*}(750) \times \mathrm{SPM} \\
= & (1-f r) \times a_{d}^{*}(750) \times \mathrm{SPM},
\end{aligned}
$$

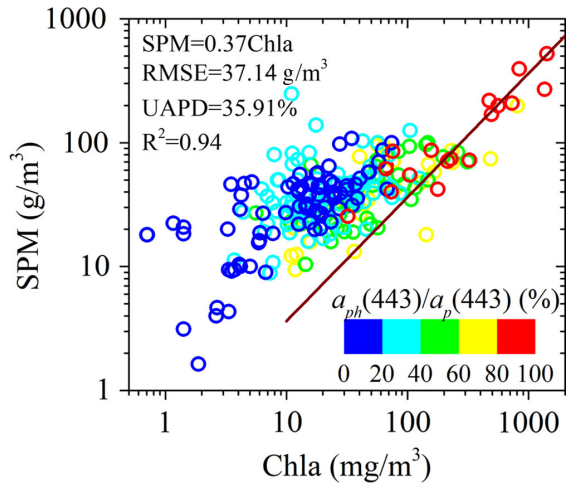

Fig. 14. Comparisons between measured Chla and SPM. Relationship between $\mathrm{SPM}_{p h}$ and Chla (solid line) was derived using data with $a_{p h}(443) / a_{p}(443)>80 \%$ (red circles).

where $a_{p h}^{*}(750)$ is the mass-specific absorption coefficient of phytoplankton at $750 \mathrm{~nm}$, which is assumed to be zero, and $a_{d}^{*}(750)$ is the mass-specific absorption coefficient of NAP at $750 \mathrm{~nm} . a_{p h}^{*}(750)$ is assumed to be zero, as it is usually below the detection limit or is lower than the obtained offset error caused by scattering [40]. We assume that $a_{d}^{*}(750)=0.014 \mathrm{~m}^{2} \mathrm{~g}^{-1}$, based on the mean value in the Elbe River measured by Röttgers et al. [40] using the IS-mode.

SPM is assumed to be dominated by phytoplankton in samples with high contributions of phytoplankton absorption to particulate absorption at $443 \mathrm{~nm}\left[a_{p h}(443) / a_{p}(443)\right]$. Indeed, we observe that SPM is strongly related to Chla in waters with $a_{p h}(443) / a_{p}(443)>80 \%$ (red circles in Fig. 14). In this case, SPM would be equal to $\mathrm{SPM}_{p h}$ if $\mathrm{SPM}_{d}$ was negligible. We therefore estimate $\operatorname{SPM}_{p h}\left(\mathrm{~g} / \mathrm{m}^{3}\right)$ from Chla $\left(\mathrm{mg} / \mathrm{m}^{3}\right)$ using the following relationship (RMSE $=37.14 \mathrm{~g} / \mathrm{m}^{3}$, $\mathrm{UAPD}=35.91 \%, \mathrm{R}^{2}=0.94$, red line in Fig. 14), derived from our data (Fig. 14):

$$
\mathrm{SPM}_{p h}=0.37 \text { Chla. }
$$

$f r$ is then derived from Chla and SPM,

$$
f r=0.37 \frac{\text { Chla }}{\text { SPM }} \text {. }
$$

In our dataset, there are 20 out of a total of 342 samples with $f r>1$; for these 20 samples, we set $f r=1(f r>1$ is not physically realistic).

$a_{p}(750)$ can then be calculated from Chla and SPM,

$$
\begin{aligned}
a_{p}(750) & =0.014 \times\left(1-0.37 \frac{\text { Chla }}{\text { SPM }}\right) \times \text { SPM } \\
& =0.014 \times(\mathrm{SPM}-0.37 \text { Chla }) .
\end{aligned}
$$

From Eq. (A5), $a_{p}(750)$ is derived from Chla and SPM, and is then used to correct the T-mode-measured $a_{d-T}(\lambda)$ and $a_{p-T}(\lambda)$ as a baseline (all the descriptions of relevant in situ data from hereon include this correction),

$$
\begin{aligned}
& a_{d}(\lambda)=a_{d-\mathrm{T}}(\lambda)+a_{p}(750), \\
& a_{p}(\lambda)=a_{p-\mathrm{T}}(\lambda)+a_{p}(750) .
\end{aligned}
$$




\section{APPENDIX B: TWO IOP INVERSION MODELS}

\section{Nonlinear Optimization Method}

The nonlinear optimization method, a simultaneous partitioning method, is built based on [2] in estimating pigment concentration. This method aims to find the best fit while allowing for variations of 40 parameters by minimizing the cost function,

$$
\chi^{2}=\sum_{i=1}^{351}\left(\frac{u_{f}\left(\lambda_{i}\right)-u_{m}\left(\lambda_{i}\right)}{u_{\text {std }}\left(\lambda_{i}\right)}\right)^{2}
$$

where the wavelength $\lambda_{i}$ ranged from 400 to $750 \mathrm{~nm}$, and $u_{f}(\lambda)$ is derived from $R_{r s}$,

$$
u_{f}(\lambda)=\frac{-g_{0}+\left[\left(g_{0}\right)^{2}+4 g_{1} r_{r s}(\lambda)\right]^{1 / 2}}{2 g_{1}},
$$

with $g_{0}=0.084, g_{1}=0.17$ [64], and

$$
r_{r s}(\lambda)=R_{r s}(\lambda) /\left(0.52+1.7 R_{r s}(\lambda)\right) .
$$

$u_{\text {std }}(\lambda)$ is the standard derivation of $u_{f}(\lambda)$ ( $f$ stands for field) based on the variability of $r_{r s}(\lambda)$ averaged for each individual inverted spectrum and serves as a weight for the cost function (so noisy wavelengths have less weight than those that are less noisy). $u_{m}(\lambda)$ ( $m$ stands for modeled) is the function of absorption, and backscattering coefficients of the modeled water constitutes

$$
\begin{aligned}
u_{m}(\lambda) & =\frac{b_{b}(\lambda)}{a(\lambda)+b_{b}(\lambda)} \\
& =\frac{b_{b p}(\lambda)+b_{b w}(\lambda)}{a_{d g}(\lambda)+a_{p h}(\lambda)+a_{w}(\lambda)+b_{b p}(\lambda)+b_{b w}(\lambda)},
\end{aligned}
$$

where $a_{w}(\lambda)$ and $b_{b w}(\lambda)$ are the known absorption and backscattering coefficients of pure water, respectively.

$b_{b p}(\lambda)$ and $a_{d g}(\lambda)$ are modeled as follows:

$$
\begin{gathered}
b_{b p}(\lambda)=b_{b p}(560)\left(\frac{560}{\lambda}\right)^{\mathrm{Y}}, \\
a_{d g}(\lambda)=a_{d g}(440) \exp \left(-S_{d g}(\lambda-440)\right) .
\end{gathered}
$$

The Gaussian peak heights $\left[a_{\text {gaus }}(\lambda)\right]$ are used to describe $a_{p h}(\lambda)$ in the Gaussian decomposition approach $[84,85]$ as follows:

$$
a_{p h}(\lambda)=\sum_{i=1}^{12} a_{\text {gaus }}\left(\lambda_{i}\right) \exp \left(-0.5\left(\frac{\lambda-\lambda_{i}}{\sigma_{i}}\right)^{2}\right)
$$

where $\lambda_{i}$ represents the center wavelength of each Gaussian peak, and $\sigma_{i}$ represents the width of each Gaussian peak. The first guess and bound values of $a_{\text {gaus }}\left(\lambda_{i}\right), \lambda_{i}$, and $\sigma_{i}$ are based on a derivative analysis of the field $a_{p h}(\lambda)$ and the previous study. The initial $\sigma_{i}$ is set as $15 \mathrm{~nm}$, and $\lambda_{i}$ and $\sigma_{i}$ were allowed to change by $\pm 5 \mathrm{~nm}$.
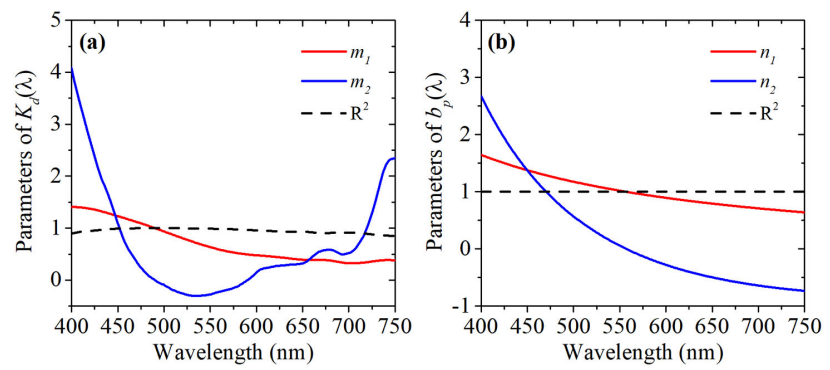

Fig. 15. (a) Parameters $\left(m_{1}, m_{2}\right)$ and $\mathrm{R}^{2}$ of the relationship between $K_{d}(\lambda)$ and $K_{d} 490$ in Eq. (B9) based on the Ecolight simulation dataset. (b) Parameters $\left(n_{1}, n_{2}\right)$ and $\mathrm{R}^{2}$ of the relationship between $b_{p}(\lambda)$ and $b_{p} 560$ in Eq. (B11) based on the Ecolight simulation dataset.

\section{Tuned LS2 Model}

The tuned LS2 model is built based on the LS2 inversion model [69], for which $R_{r s}(\lambda)$, SPIM, and the sun zenith angle are the input parameters. Several steps of LS2 are tuned using the fieldmeasured data in this study, and the Ecolight simulation data in the study of [86], which used the field data in Lake Chaohu. The differences from the LS2 model are as follows:

(1) Step 2 of Table 1 in Ref. [69]:

Downwelling diffuse attenuation coefficient at $490 \mathrm{~nm}$, $K_{d} 490$, is derived using the model built for Lake Taihu [63],

$$
K_{d} 490=11.89 \frac{R_{r s}(681)}{R_{r s}(560)}+6.81 \frac{R_{r s}(750)}{R_{r s}(560)}-6.17 .
$$

Downwelling diffuse attenuation coefficient, $K_{d}(\lambda)$, is then derived from $K_{d} 490$ with two parameters $\left[m_{1}(\lambda)\right.$, $m_{2}(\lambda)$, Fig. 15] based on the Ecolight simulation dataset,

$$
K_{d}(\lambda)=m_{1}(\lambda) \times K_{d} 490+m_{2}(\lambda) .
$$

(2) Step 2 of Table 1 in Ref. [69]:

Scattering coefficient of particulate at $560 \mathrm{~nm}, b_{p} 560$, is related to SPIM using the Ecolight Simulation data,

$$
b_{p} 560=12.37 \exp (0.023 \times \mathrm{SPIM}) .
$$

Scattering coefficient, $b(\lambda)$, is then derived from $b_{p} 560$ with two parameters $\left[n_{1}(\lambda), n_{2}(\lambda)\right.$, Fig. 15$]$ based on the Ecolight simulation dataset and $b_{b w}(\lambda)[65]$,

$$
b(\lambda)=n_{1}(\lambda) \times b_{p} 560+n_{2}(\lambda)+2 \times b_{b w}(\lambda) .
$$

The lookup table of parameters $\left(a_{1}-a_{4}, b_{b 1}-b_{b 3}\right.$, see Data File 1) in Eqs. (B12), (B12) was rebuilt using the Ecolight simulation data based on the bio-optical properties in Lake Chaohu, China [86].

$$
a(\lambda)=\frac{K_{d}(\lambda)}{a_{1}\left(\eta, \mu_{w}\right) R_{r s}(\lambda)^{3}+a_{2}\left(\eta, \mu_{w}\right) R_{r s}(\lambda)^{2}+a_{3}\left(\eta, \mu_{w}\right) R_{r s}(\lambda)+a_{4}\left(\eta, \mu_{w}\right)},
$$




$$
\begin{aligned}
b_{b}(\lambda) & =K_{d}(\lambda) \times\left[b_{b_{1}}\left(\eta, \mu_{w}\right) R_{r s}(\lambda)^{3}\right. \\
& \left.+b_{b 2}\left(\eta, \mu_{w}\right) R_{r s}(\lambda)^{2}+b_{b 3}\left(\eta, \mu_{w}\right) R_{r s}(\lambda)\right] .
\end{aligned}
$$

Funding. National Natural Science Foundation of China (41431176, 41701416, 41771366); Natural Science Foundation of Jiangsu Province (BK20181509); NIGLAS project (NIGLAS2017GH03).

Acknowledgment. We thank the colleagues from NIGLAS (Dian Wang, Zhigang Cao, Junfeng Xiong, Minqi $\mathrm{Hu}$, Tianci Qi, Jinge Ma, Qiao Chu, and Pengfei Zhan) for their help with field measurements and data collections. We thank Alison Chase, Hubert Loisel, and Rüdiger Röttgers for their help and suggestions in model development.

\section{REFERENCES}

1. A. Bricaud, C. Mejia, D. Blondeau-Patissier, H. Claustre, M. Crepon, and S. Thiria, "Retrieval of pigment concentrations and size structure of algal populations from their absorption spectra using multilayered perceptrons," Appl. Opt. 46, 1251-1260 (2007).

2. A. P. Chase, E. Boss, I. Cetinić, and W. Slade, "Estimation of phytoplankton accessory pigments from hyperspectral reflectance spectra: toward a global algorithm," J. Geophys. Res. Oceans 122, 9725-9743 (2017).

3. C. Mitchell and A. Cunningham, "Remote sensing of spatio-temporal relationships between the partitioned absorption coefficients of phytoplankton cells and mineral particles and euphotic zone depths in a partially mixed shelf sea," Remote Sens. Environ. 160, 193-205 (2015).

4. M. K. Barnes, G. H. Tilstone, T. J. Smyth, D. J. Suggett, R. Astoreca, C. Lancelot, and J. C. Kromkamp, "Absorption-based algorithm of primary production for total and size-fractionated phytoplankton in coastal waters," Mar. Ecol. Prog. Ser. 504, 73-89 (2014).

5. J. Marra, C. C. Trees, and J. E. O'Reilly, "Phytoplankton pigment absorption: a strong predictor of primary productivity in the surface ocean," Deep Sea Res. Part I 54, 155-163 (2007).

6. D. Stramski, R. A. Reynolds, M. Kahru, and B. G. Mitchell, "Estimation of particulate organic carbon in the ocean from satellite remote sensing," Science 285, 239-242 (1999).

7. T. Kutser, D. C. Pierson, K. Y. Kallio, A. Reinart, and S. Sobek, "Mapping lake CDOM by satellite remote sensing," Remote Sens. Environ. 94, 535-540 (2005).

8. J. Uitz, D. Stramski, R. A. Reynolds, and J. Dubranna, "Assessing phytoplankton community composition from hyperspectral measurements of phytoplankton absorption coefficient and remote-sensing reflectance in open-ocean environments," Remote Sens. Environ. 171, 58-74 (2015).

9. H. Xi, M. Hieronymi, R. Röttgers, H. Krasemann, and Z. Qiu, "Hyperspectral differentiation of phytoplankton taxonomic groups: a comparison between using remote sensing reflectance and absorption spectra," Remote Sens. 7, 14781-14805 (2015).

10. P. J. Werdell, C. S. Roesler, and J. I. Goes, "Discrimination of phytoplankton functional groups using an ocean reflectance inversion model," Appl. Opt. 53, 4833-4849 (2014).

11. C. B. Mouw, N. J. Hardman-Mountford, S. Alvain, A. Bracher, R. J. W. Brewin, A. Bricaud, A. M. Ciotti, E. Devred, A. Fujiwara, T. Hirata, T. Hirawake, T. S. Kostadinov, S. Roy, and J. Uitz, "A consumer's guide to satellite remote sensing of multiple phytoplankton groups in the global ocean," Front. Mar. Sci. 4, 41 (2017).

12. Z. Lee, Remote Sensing of Inherent Optical Properties: Fundamentals, Tests of Algorithms, and Applications (IOCCG, 2006).

13. S. Mishra, D. R. Mishra, Z. Lee, and C. S. Tucker, "Quantifying cyanobacterial phycocyanin concentration in turbid productive waters: a quasi-analytical approach," Remote Sens. Environ. 133, 141-151 (2013).
14. W. Yang, B. Matsushita, J. Chen, K. Yoshimura, and T. Fukushima, "Retrieval of inherent optical properties for turbid inland waters from remote-sensing reflectance," IEEE Trans. Geosci. Remote Sens. 51, 3761-3773 (2013).

15. S. Mishra, D. R. Mishra, and Z. Lee, "Bio-optical inversion in highly turbid and cyanobacteria-dominated waters," IEEE Trans. Geosci. Remote Sens. 52, 375-388 (2014).

16. I. Ogashawara, D. R. Mishra, R. F. F. Nascimento, E. H. Alcântara, M. Kampel, and J. L. Stech, "Re-parameterization of a quasi-analytical algorithm for colored dissolved organic matter dominant inland waters," Int. J. Appl. Earth Obs. 53, 128-145 (2016).

17. S. A. Garver and D. A. Siegel, "Inherent optical property inversion of ocean color spectra and its biogeochemical interpretation: 1. Time series from the Sargasso sea," J. Geophys. Res. 102, 18607-18625 (1997).

18. Z. Lee, K. L. Carder, and R. A. Arnone, "Deriving inherent optical properties from water color: a multiband quasi-analytical algorithm for optically deep waters," Appl. Opt. 41, 5755-5772 (2002).

19. H. Loisel and D. Stramski, "Estimation of the inherent optical properties of natural waters from the irradiance attenuation coefficient and reflectance in the presence of Raman scattering," Appl. Opt. 39, 3001-3011 (2000).

20. M. Hieronymi, D. Müller, and R. Doerffer, "The OLCI neural network swarm (ONNS): a bio-geo-optical algorithm for open ocean and coastal waters," Front. Mar. Sci. 4, 140 (2017).

21. A. B. Ruescas, M. Hieronymi, G. Mateo-Garcia, S. Koponen, K. Kallio, and G. Camps-Valls, "Machine learning regression approaches for colored dissolved organic matter (CDOM) retrieval with S2-MSI and S3-OLCl simulated data," Remote Sens. 10, 786 (2018).

22. P. J. Werdell, L. I. W. McKinna, E. Boss, S. G. Ackleson, S. E. Craig, W. W. Gregg, Z. Lee, S. Maritorena, C. S. Roesler, C. S. Rousseaux, D. Stramski, J. M. Sullivan, M. S. Twardowski, M. Tzortziou, and X. Zhang, "An overview of approaches and challenges for retrieving marine inherent optical properties from ocean color remote sensing," Prog. Oceanogr. 160, 186-212 (2018).

23. A. M. Ciotti and A. Bricaud, "Retrievals of a size parameter for phytoplankton and spectral light absorption by colored detrital matter from water-leaving radiances at SeaWiFS channels in a continental shelf region off Brazil," Limnol. Oceanogr. 4, 237-253 (2006).

24. G. Zheng and D. Stramski, "A model for partitioning the light absorption coefficient of suspended marine particles into phytoplankton and nonalgal components," J. Geophys. Res. 118, 2977-2991 (2013).

25. P. Ylöstalo, K. Kallio, and J. Seppälä, "Absorption properties of inwater constituents and their variation among various lake types in the boreal region," Remote Sens. Environ. 148, 190-205 (2014).

26. J. Meler, M. Ostrowska, D. Ficek, and A. Zdun, "Light absorption by phytoplankton in the southern Baltic and Pomeranian lakes: mathematical expressions for remote sensing applications," Oceanologia 59, 195-212 (2017).

27. C. Binding, J. Jerome, R. Bukata, and W. Booty, "Spectral absorption properties of dissolved and particulate matter in Lake Erie," Remote Sens. Environ. 112, 1702-1711 (2008).

28. P. J. Werdell and S. W. Bailey, "An improved in-situ bio-optical data set for ocean color algorithm development and satellite data product validation," Remote Sens. Environ. 98, 122-140 (2005).

29. K. Xue, R. Ma, H. Duan, M. Shen, E. Boss, and Z. Cao, "Inversion of inherent optical properties in optically complex waters using sentinel$3 \mathrm{~A} / \mathrm{OLCl}$ images: a case study using China's three largest freshwater lakes," Remote Sens. Environ. 225, 328-346 (2019).

30. C. Andrade, E. Alcântara, N. Bernardo, and M. Kampel, "An assessment of semi-analytical models based on the absorption coefficient in retrieving the chlorophyll-a concentration from a reservoir," Adv. Space Res. 63, 2175-2188 (2019).

31. L. Li, L. Li, K. Song, Y. Li, L. P. Tedesco, K. Shi, and Z. Li, “An inversion model for deriving inherent optical properties of inland waters: establishment, validation and application," Remote Sens. Environ. 135, 150-166 (2013).

32. C. Le, Y. Li, Y. Zha, and D. Sun, "Specific absorption coefficient and the phytoplankton package effect in Lake Taihu, China," Hydrobiologia 619, 27-37 (2009).

33. C. B. Mouw, H. Chen, G. A. McKinley, S. Effler, D. O'Donnell, M. G. Perkins, and C. Strait, "Evaluation and optimization of bio-optical 
inversion algorithms for remote sensing of Lake Superior's optical properties," J. Geophys. Res. 118, 1696-1714 (2013).

34. F. Watanabe, D. R. Mishra, I. Astuti, T. Rodrigues, E. Alcântara, N. N. Imai, and C. Barbosa, "Parametrization and calibration of a quasianalytical algorithm for tropical eutrophic waters," ISPRS J. Photogr. Remote Sens. 121, 28-47 (2016).

35. C. Le, Y. Li, Y. Zha, D. Sun, and B. Yin, "Validation of a quasi-analytical algorithm for highly turbid eutrophic water of Meiliang Bay in Taihu Lake, China," IEEE Trans. Geosci. Remote Sens. 47, 2492-2500 (2009).

36. W. Shi and M. Wang, "A blended inherent optical property algorithm for global satellite ocean color observations," Limnol. Oceanogr. 17, 377-394 (2019).

37. R. Ma, H. Duan, C. Hu, X. Feng, A. Li, W. Ju, J. Jiang, and G. Yang, "A half-century of changes in China's lakes: global warming or human influence?" Geophys. Res. Lett. 37, L24106 (2010).

38. Z. Shi, Y. Zhang, M. Liu, X. Yuan, Y. Yin, and X. Liu, "Spectral absorption coefficients of particulate matter in Lake Donghu, Lake Liangzihu, and Lake Honghu," Resour. Environ. Yangtze Basin 736-743 (2011).

39. A. R. Neeley and A. Mannino, eds., Inherent Optical Property Measurements and Protocols: Absorption Coefficient (IOCCG, 2018).

40. R. Röttgers, C. Dupouy, B. B. Taylor, A. Bracher, and S. B. Woźniak, "Mass-specific light absorption coefficients of natural aquatic particles in the near-infrared spectral region," Limnol. Oceanogr. 59, 1449-1460 (2014).

41. H. Duan, M. Tao, S. A. Loiselle, W. Zhao, Z. Cao, R. Ma, and X. Tang, "MODIS observations of cyanobacterial risks in a eutrophic lake: implications for long-term safety evaluation in drinking-water source," Water Res. 122, 455-470 (2017).

42. Z. Cao, H. Duan, L. Feng, R. Ma, and K. Xue, "Climate- and humaninduced changes in suspended particulate matter over Lake Hongze on short and long timescales," Remote Sens. Environ. 192, 98-113 (2017).

43. Y. Zhang, K. Shi, Y. Zhou, X. Liu, and B. Qin, "Monitoring the river plume induced by heavy rainfall events in large, shallow, Lake Taihu using MODIS 250 m imagery," Remote Sens. Environ. 173, 109-121 (2016).

44. L. Feng, C. Hu, X. Chen, L. Tian, and L. Chen, "Human induced turbidity changes in Poyang Lake between 2000 and 2010: observations from MODIS," J. Geophys. Res. 117, C07006 (2012).

45. C. D. Mobley, "Estimation of the remote-sensing reflectance from above-surface measurements," Appl. Opt. 38, 7442-7455 (1999).

46. B. G. Mitchell, M. Kahru, J. Wieland, and M. Stramska, Determination of Spectral Absorption Coefficients of Particles, Dissolved Material and Phytoplankton for Discrete Water Samples (Citeseer, 2003).

47. B. G. Mitchell, "Algorithms for determining the absorption coefficient of aquatic particulates using the quantitative filter technique," Proc. SPIE 1302, 137-148 (1990).

48. G. M. Ferrari and S. Tassan, "A method using chemical oxidation to remove light absorption by phytoplankton pigments," J. Phycol. 35, 1090-1098 (1999).

49. Y. Zhang, B. Zhang, X. Wang, J. Li, S. Feng, Q. Zhao, M. Liu, and B. Qin, "A study of absorption characteristics of chromophoric dissolved organic matter and particles in Lake Taihu, China," Hydrobiologia 592, 105-120 (2007).

50. J. S. Cleveland and A. D. Weidemann, "Quantifying absorption by aquatic particles: a multiple scattering correction for glass-fiber filters," Limnol. Oceanogr. 38, 1321-1327 (1993).

51. R. M. Pope and E. S. Fry, "Absorption spectrum $(380-700 \mathrm{~nm})$ of pure water. II. Integrating cavity measurements," Appl. Opt. 36, 8710-8723 (1997).

52. A. A. Gitelson, G. Dall'Olmo, W. Moses, D. C. Rundquist, T. Barrow, T. R. Fisher, D. Gurlin, and J. Holz, "A simple semi-analytical model for remote estimation of chlorophyll-a in turbid waters: validation," Remote Sens. Environ. 112, 3582-3593 (2008).

53. P. J. Werdell, B. A. Franz, S. W. Bailey, G. C. Feldman, E. Boss, V. E. Brando, M. Dowell, T. Hirata, S. J. Lavender, Z. Lee, H. Loisel, S. Maritorena, F. Mélin, T. S. Moore, T. J. Smyth, D. Antoine, E. Devred, O. H. F. d'Andon, and A. Mangin, "Generalized ocean color inversion model for retrieving marine inherent optical properties," Appl. Opt. 52, 2019-2037 (2013).

54. G. Jiang, R. Ma, S. A. Loiselle, and H. Duan, "Optical approaches to examining the dynamics of dissolved organic carbon in optically complex inland waters," Environ. Res. Lett. 7, 034014 (2012).

55. K. Xue, Y. Zhang, H. Duan, and R. Ma, "Variability of light absorption properties in optically complex inland waters of Lake Chaohu, China," J. Great Lakes Res. 43, 17-31 (2017).

56. G. Wu, L. Cui, H. Duan, T. Fei, and Y. Liu, "Absorption and backscattering coefficients and their relations to water constituents of Poyang Lake, China," Appl. Opt. 50, 6358-6368 (2011).

57. E. F. Vermote, D. Tanre, J. L. Deuze, M. Herman, and J. J. Morcette, "Second simulation of the satellite signal in the solar spectrum, 6S: an overview," IEEE Trans. Geosci. Remote Sens. 35, 675-686 (1997).

58. C. Brockmann, R. Doerffer, M. Peters, S. Kerstin, S. Embacher, and A. Ruescas, "Evolution of the C2RCC neural network for Sentinel 2 and 3 for the retrieval of ocean colour products in normal and extreme optically complex waters," in Living Planet Symposium (2016), p. 54.

59. F. Steinmetz, P.-Y. Deschamps, and D. Ramon, "Atmospheric correction in presence of sun glint: application to MERIS," Opt. Express 19, 9783-9800 (2011).

60. K. Xue, R. Ma, D. Wang, and M. Shen, "Optical classification of the remote sensing reflectance and its application in deriving the specific phytoplankton absorption in optically complex lakes," Remote Sens. 11, 184 (2019).

61. C. Hu, "A novel ocean color index to detect floating algae in the global oceans," Remote Sens. Environ. 113, 2118-2129 (2009).

62. Y. Zhang, R. Ma, H. Duan, S. A. Loiselle, J. Xu, and M. Ma, "A novel algorithm to estimate algal bloom coverage to subpixel resolution in Lake Taihu," IEEE J. Sel. Top. Appl. Earth Obs. Remote Sens. 7, 3060-3068 (2014).

63. M. Shen, H. Duan, Z. Cao, K. Xue, S. Loiselle, and H. Yesou, "Determination of the downwelling diffuse attenuation coefficient of lake water with the sentinel-3A OLCI," Remote Sens. 9, 1246 (2017).

64. Z. Lee, K. L. Carder, C. D. Mobley, R. G. Steward, and J. S. Patch, "Hyperspectral remote sensing for shallow waters: 2. Deriving bottom depths and water properties by optimization," Appl. Opt. $\mathbf{3 8}$, 3831-3843 (1999).

65. A. Morel, "Optical properties of pure water and pure sea water," in Optical Aspects of Oceanography, N. G. Jerlov and E. S. Nielsen, eds. (Academic, 1974), pp. 1-24.

66. H. R. Gordon, O. B. Brown, R. H. Evans, J. W. Brown, R. C. Smith, K. S. Baker, and D. K. Clark, "A semianalytic radiance model of ocean color," J. Geophys. Res. Atmos. 93, 10909-10924 (1988).

67. E. S. Boss, R. Collier, G. Larson, K. Fennel, and W. S. Pegau, "Measurements of spectral optical properties and their relation to biogeochemical variables and processes in Crater Lake, Crater Lake National Park, OR," Hydrobiologia 574, 149-159 (2007).

68. B. B. Barnes, R. Garcia, C. Hu, and Z. Lee, "Multi-band spectral matching inversion algorithm to derive water column properties in optically shallow waters: an optimization of parameterization," Remote Sens. Environ. 204, 424-438 (2018).

69. H. Loisel, D. Stramski, D. Dessailly, C. Jamet, L. Li, and R. A. Reynolds, "An inverse model for estimating the optical absorption and backscattering coefficients of seawater from remote-sensing reflectance over a broad range of oceanic and coastal marine environments," J. Geophys. Res. 123, 2141-2171 (2018).

70. G. Wang, Z. Lee, D. R. Mishra, and R. Ma, "Retrieving absorption coefficients of multiple phytoplankton pigments from hyperspectral remote sensing reflectance measured over cyanobacteria bloom waters," Limnol. Oceanogr. 14, 432-447 (2016).

71. C. D. Mobley and L. K. Sundman, "Hydrolight 5-Ecolight 5 Technical Documentation," Sequoia Science, 2008.

72. I. Lefering, R. Rottgers, R. Weeks, D. Connor, C. Utschig, K. Heymann, and D. McKee, "Improved determination of particulate absorption from combined filter pad and PSICAM measurements," Opt. Express 24, 24805-24823 (2016).

73. D. Stramski, M. Babin, and S. B. Woźniak, "Variations in the optical properties of terrigenous mineral-rich particulate matter suspended in seawater," Limnol. Oceanogr. 52, 2418-2433 (2007). 
74. M. Babin, D. Stramski, G. M. Ferrari, H. Claustre, A. Bricaud, G. Obolensky, and N. Hoepffner, "Variations in the light absorption coefficients of phytoplankton, nonalgal particles, and dissolved organic matter in coastal waters around Europe," J. Geophys. Res. 108, 3211 (2003).

75. D. Stramski, R. A. Reynolds, S. Kaczmarek, J. Uitz, and G. Zheng, "Correction of pathlength amplification in the filter-pad technique for measurements of particulate absorption coefficient in the visible spectral region," Appl. Opt. 54, 6763-6782 (2015).

76. R. Röttgers and S. Gehnke, "Measurement of light absorption by aquatic particles: improvement of the quantitative filter technique by use of an integrating sphere approach," Appl. Opt. 51, 1336-1351 (2012).

77. L. Li, L. Li, and K. Song, "Remote sensing of freshwater cyanobacteria: an extended IOP Inversion Model of Inland Waters (IIMIW) for partitioning absorption coefficient and estimating phycocyanin," Remote Sens. Environ. 157, 9-23 (2015).

78. W. Zhu, Q. Yu, Y. Q. Tian, R. F. Chen, and G. B. Gardner, "Estimation of chromophoric dissolved organic matter in the Mississippi and Atchafalaya river plume regions using above-surface hyperspectral remote sensing," J. Geophys. Res. 116, C02011 (2011).

79. X. Zhang, Y. Huot, A. Bricaud, and H. M. Sosik, "Inversion of spectral absorption coefficients to infer phytoplankton size classes, chlorophyll concentration, and detrital matter," Appl. Opt. 54, 5805-5816 (2015).
80. G. Zheng, D. Stramski, and P. M. DiGiacomo, "A model for partitioning the light absorption coefficient of natural waters into phytoplankton, nonalgal particulate, and colored dissolved organic components: a case study for the Chesapeake Bay," J. Geophys. Res. 120, 2601-2621 (2015).

81. D. Stramski, L. Li, and R. A. Reynolds, "Model for separating the contributions of non-algal particles and colored dissolved organic matter to light absorption by seawater," Appl. Opt. 58, 3790-3806 (2019).

82. J. Wei, Z. Lee, S. Shang, and X. Yu, "Semi-analytical derivation of phytoplankton, CDOM, and detritus absorption coefficients from the Landsat 8/OLI reflectance in coastal waters," J. Geophys. Res. 124, 3682-3699 (2019)

83. D. Wang, R. Ma, K. Xue, and S. A. Loiselle, "The assessment of Landsat-8 OLI atmospheric correction algorithms for inland waters," Remote Sens. 11, 169 (2019).

84. N. Hoepffner and S. Sathyendranath, "Effect of pigment composition on absorption properties of phytoplankton," Mar. Ecol. Prog. Ser. 73, 11-23 (1991).

85. A. Bricaud and A. Morel, "Light attenuation and scattering by phytoplanktonic cells: a theoretical modeling," Appl. Opt. 25, 571-580 (1986).

86. K. Xue, Y. Zhang, R. Ma, and H. Duan, "An approach to correct the effects of phytoplankton vertical nonuniform distribution on remote sensing reflectance of cyanobacterial bloom waters," Limnol. Oceanogr. 15, 302-319 (2017). 